Article

\title{
Drying of Lignite of Various Origins in a Pilot Scale Toroidal Fluidized Bed Dryer using Low Quality Heat
}

\author{
Halina Pawlak-Kruczek ${ }^{1, *}$, Michał Czerep ${ }^{1}$, , Lukasz Niedzwiecki ${ }^{1}{ }^{\circledR}$, \\ Emmanouil Karampinis ${ }^{2}{ }^{\mathbb{D}}$, Ioannis Violidakis ${ }^{2}$, Ioannis Avagianos ${ }^{2}$ and \\ Panagiotis Grammelis ${ }^{2}$ \\ 1 Wroclaw University of Science and Technology, Faculty of Mechanical and Power Engineering, \\ Department of Boilers, Combustion and Energy Processes, 59-400 Wrocław, Poland; \\ michal.czerep@pwr.edu.pl (M.C.); lukasz.niedzwiecki@pwr.edu.pl (L.N.) \\ 2 Centre for Research and Technology Hellas, Chemical Process and Energy Resources Institute, \\ GR 50200 Ptolemais, Greece; karampinis@certh.gr (E.K.); violidakis@certh.gr (I.V.); \\ avagianos@lignite.gr (I.A.); grammelis@certh.gr (P.G.) \\ * Correspondence: halina.pawlak@pwr.edu.pl
}

Received: 3 February 2019; Accepted: 21 March 2019; Published: 27 March 2019

\begin{abstract}
An experimental study was carried out for lignites of different places of origin, i.e., Poland, Greece, Romania and Australia, using a toroidal bed dryer. The effect of the temperature on the drying efficiency, including the loss of moisture content over time under fixed drying conditions was the subject of the investigation. The main goal was to confirm the possibility of the use of a toroidal bed as a base for a drying system that could utilize low quality heat from sources such as flue gases from a boiler and determine the optimum parameters for such a system. The conducted study has conclusively proven the feasibility of the use of low temperature heat sources for drying lignite in a toroidal bed. A moisture content of $20 \%$ could be achieved for most of the tested lignites, using the toroidal bed, with reasonably short residence times (approx. $30 \mathrm{~min}$ ) and an air temperature as low as $60{ }^{\circ} \mathrm{C}$. Moreover, the change of the particle size distribution, to some degree, affected the final moisture content due to the entrainment of wet, fine particles. The study also determined that the in-bed attrition of the particles is partially responsible for the generation of fines.
\end{abstract}

Keywords: drying; lignite; toroidal bed; attrition; energy efficiency

\section{Introduction}

\subsection{Drying of Lignite}

Lignite is a solid fossil fuel that is mostly used for power generation. Despite recent increases in the installed renewable energy source power, the use of lignite is still significant all over the world. In 2015 worldwide mining of lignite reached almost 811 million tons [1], including 399 million tons mined across the EU [2]; the share of power production originating from lignite exceeds $20 \%$ in several countries such as Australia, Bulgaria, Czech, Germany, Greece, Poland, Romania, Serbia and others [2]. Lignite is a low rank solid fuel [3], characterized by high moisture content. Reducing the moisture content of lignite prior to its utilization can increase its calorific value, reduce the cost of its long distance transport and reduce greenhouse gas emissions from its utilization. Drying is also a typical pre-requisite for technologies aiming to produce high-added value products from lignite, such as soil amendments [4]. Therefore, an investigation aimed to rationalize the use of lignite and in the same time utilize the low grade heat, that would have been wasted otherwise, seems to be well justified.

A lot of work has been performed recently on fundamental aspects of lignite drying. Park et al. investigated the impact of the drying time, temperature and the velocity of the drying agent on the 
drying efficiency of Indonesian lignite and developed a mathematical model that would allow the prediction of the moisture content depending on the residence time and drying conditions [5]. Si et al. investigated a 3-stage microwave assisted fluidized bed drying of Shengli lump lignite and determined that the porosity of the dried lignite decreased with increasing power of the microwaves [6]. Song et al. determined that the overall moisture content of the lignite from eastern Inner Mongolia decreased more rapidly under higher microwave power [7]. Pusat and Herdem determined the drying characteristics of the Turkish Konya-Ilgin lignite in a fixed bed dryer [8]. The study determined that the required drying time increased with an increase of the bed height, and the effect of the temperature on the drying rate increased with an increase of the bed height [8]. Yang et al. experimentally tested re-absorption of moisture by lignite after drying in a fixed bed and determined the highest re-absorbed moisture yield for lignite dried in $100{ }^{\circ} \mathrm{C}$ due to the high relative volume ratio of mesopores [9]. Feng et al. investigated the effect of the Mechanical Thermal Expression on the structure of lignite and determined changes in volume of pores between the raw lignite and lignites dried at drying temperatures between $120^{\circ} \mathrm{C}$ and $150^{\circ} \mathrm{C}$ under pressures of $10 \mathrm{MPa}$ and $30 \mathrm{MPa}$ respectively [10]. Wen et al. investigated the drying kinetics of raw and re-moisturised lignite and determined the drying rate of the former was slower in comparison to the latter [11]. Moreover, the study found the effective diffusion coefficient for the moisturised lignite to be higher than a corresponding value for a raw lignite [11].

Pawlak-Kruczek et al. conducted a study that involved both experimental investigation and numerical simulation of lignite drying in a fluidized bed, using a low temperature drying agent (air, max. $50^{\circ} \mathrm{C}$ ) [12]. The study has proven the overall feasibility of the concept of utilization of a low temperature heat source. Moreover, the study revealed importance of factors such as structural properties of the lignite along with its shrinkage during drying [12]. Agraniotis et al. compared CFD simulations with experimental results from a $1 \mathrm{MW}_{\text {th }}$ pulverised fuel combustion facility [13]. Results showed good agreement between the simulation and the experimental results. Temperatures measured along the axis of the furnace, especially at the bottom part of the furnace, were highest for the case of firing of dry lignite, where vapours and carrier gas were not re-circulated into the furnace [13]. This seems to be in good agreement with results of another study, conducted by Tahmasebi et al. which investigated relationship between the moisture content and ignition of the particles of Chinese and Indonesian lignite [14]. This study determined that increase in the moisture content of the tested lignite significantly delayed their ignition [14]. Numerical simulations, performed by Drosatos et al. demonstrated that the use of pre-dried lignite can improve the flexibility of the boiler and allow its operation under extremely low load, equal to $35 \%$ of the nominal load [15]. Komatsu et al. conducted experiments involving drying of coarse particles of lignite, using superheated steam at $110{ }^{\circ} \mathrm{C}$ up to $170{ }^{\circ} \mathrm{C}$ [16]. The study concluded that value of drying rate, during constant drying rate period depended solely on the temperature and particle size of lignite, whereas relationship during the decreasing drying rate period was much more complicated due to the cracks, that started to form on the surface of the dried particle [16]. Pusat et al. investigated drying of the Turkish lignite in a fixed bed, using drying air at temperatures between $70{ }^{\circ} \mathrm{C}$ and $130{ }^{\circ} \mathrm{C}$ and velocities between 0.4 and $1.1 \mathrm{~m} / \mathrm{s}$ [17]. Particle size of the lignite varied between 20 and $50 \mathrm{~mm}$ and for such coarse particles a constant drying rate period was not observed during the performed experiments [17]. Sciazko et al. performed experimental investigations on the influence of petrographic properties on the drying characteristics of Turoszów lignite in superheated steam drying [18]. Investigation was performed, using $5 \mathrm{~mm}$ and $10 \mathrm{~mm}$ spherical particles, with temperatures ranging from $110^{\circ} \mathrm{C}$ to $170{ }^{\circ} \mathrm{C}[18]$ and concluded that drying time, drying rate, temperature gradients, cracking and shrinking behaviour are dependent on the lithotype of tested lignite [18].

Breakage and attrition during drying of Australian lignite in a fixed bed and fluidized bed at temperature of $130{ }^{\circ} \mathrm{C}$ were the subject of an extensive study performed by Stokie et al. [19]. The study concluded that the main reason for breakage is the transition between bulk and non-freezable water [19]. Changes of the particle size between small fixed bed and small fluidized bed (sample of $10 \mathrm{~g}$ ), indicated by $\mathrm{d}_{50}$ diameter, were insignificant. Nonetheless, a significant difference in the change in the particle 
size was noted for the big fluidized bed (sample size $3 \mathrm{~kg}$ ) indicating the large influence of the effect of the scale of the bed.

\subsection{Toroidal Bed Reactor}

The toroidal fluidized bed reactor is a special type of fluidized bed reactor, with a gas distribution system that consists of angled blades, located at the bottom of the reactor [20]. This arrangement allows intensification of the bed performance [21,22], i.e., intensification of heat and mass transfer $[20,21]$ as well as improved mixing $[21,23,24]$. This is due to the vortex flow pattern and is characteristic for all vortex reactors [24-27]. In terms of the reactor's performance it allows increased throughput (increased productivity) with reduced residence times [28]. Most of the work published so far, on such types of bed, involves various types of thermal processing [29,30], calcination process [31] or intensification of the sorption for carbon capture [32]. There is scarce information on drying in such fluidized beds with toroidal flow patterns [33]. This study aims to address this knowledge gap.

\subsection{Aims, Scope and Novelty Aspects of the Performed Work}

As shown in Section 1.1, lignite drying is a complex process, dependent on many parameters (temperature, residence time, drying agent, drying method and properties of the lignite). There is a knowledge gap, concerning the drying kinetics and energy consumption for drying in highly turbulent toroidal beds. Moreover, it is a pre-requisite for any studies aiming at integration of such dryers, using low quality waste heat, into lignite power plants. This would allow one to compare potential savings of the use of novel solutions with energy savings, already demonstrated for existing lignite drying solutions, using drying agents at higher temperatures [34-46].

This study aims to fill that gap by investigation on the drying of lignites of various origins in a toroidal bed, using air as a drying agent. It was expected that such a configuration will cause the mass and heat transfer to be intensified, subsequently enabling the use of the drying agent at a relatively low temperature. An experimental study, using a toroidal bed dryer, was carried out for lignites of different countries of origin, i.e., Poland, Greece, Romania and Australia. The effect of the temperature on the efficiency of drying, including the loss of moisture content over time at fixed drying conditions was a subject of the investigation. The kinetics of drying and energy consumption during the drying at different average temperatures were determined and compared. The study aimed to identify the optimum of the drying process parameters, i.e., temperature and residence time, taking into account drying rate and energy consumption. However, other factors, such as relative humidity of the drying agent along with the inherent properties of the feedstock also had a profound influence on the drying process. The methodology used in the study is universally applicable for drying processes in general. In that respect, the performed suite of experiments can be treated as a case study that proves the wide applicability of the test method.

The main purpose of the performed study was to confirm the possibility of using a toroidal bed as a base for a drying system that could utilize low quality heat from sources such as flue gases from a boiler. Such a type of the fluidized bed dryer has never been used for drying lignite which, along with potential use of low quality heat, underlines the novelty of the performed study. Moreover, the performed study aimed to find the most effective dryer parameters, i.e., the parameters that enable to one achieve the minimum consumption of energy to remove $1 \mathrm{~kg} \mathrm{H}_{2} \mathrm{O}$ contained at the surface and the pores of lignite particles.

\section{Materials and Methods}

\subsection{Characteristics of the Tested Lignites}

Samples of Polish lignite were obtained from the Sieniawa open cast mine. Lignite from Sieniawa consists predominantly of xylodetritic and detroxylytic lithotypes [47]. Greek lignite was obtained from the South Field mine that supplies the Agios Dimitrios power plant operated by the Public Power 
Corporation. A sample of Romanian lignite was taken from the Pesteana mine, which provide fuel to the Rovinari power plant of the Oltenia Energy Complex. Australian lignite was obtained from the Yallourn mine in the Latrobe Valley, which feeds the Yallourn power plant of Energy Australia. All of the lignites had been pre-crushed to the nominal top size of $8 \mathrm{~mm}$, prior to the performed tests.

Basic characterisation of lignites used for this study was performed by means of proximate and ultimate analysis, which is typical way to characterise solid fuels. Proximate analysis of the lignites (Table 1) was performed using a Perkin Elmer Diamond TGA (331 Treble Cove Rd., Billerica, MA 01862, USA). The following program was applied during these tests:

- (1) Initial stage

- Heat up to $105^{\circ} \mathrm{C}$; ramp $10^{\circ} \mathrm{C} / \mathrm{min}$

- Hold $10 \mathrm{~min}$

- (2 a) To obtain ash content air was used:

- Heat up to $815^{\circ} \mathrm{C}$; $\operatorname{ramp} 50^{\circ} \mathrm{C} / \mathrm{min}$

- Hold $15 \mathrm{~min}$

- $\quad(2 \mathrm{~b})$ To obtain volatile matter content argon was used:

○ $\quad$ Heat up to $850{ }^{\circ} \mathrm{C}$; $\operatorname{ramp} 50^{\circ} \mathrm{C} / \mathrm{min}$

- Hold $15 \mathrm{~min}$

Table 1. Proximate and elemental analysis of tested lignites.

\begin{tabular}{|c|c|c|c|c|c|c|}
\hline Parameter & Symbol & $\begin{array}{c}\text { Polish } \\
\text { (Sieniawa) }\end{array}$ & $\begin{array}{c}\text { Greek (Agios } \\
\text { Dimitrios) }\end{array}$ & $\begin{array}{l}\text { Romanian } \\
\text { (Peșteana) }\end{array}$ & $\begin{array}{l}\text { Australian } \\
\text { (Yallourn) }\end{array}$ & Unit \\
\hline Moisture content ${ }^{1}$ & MC & 42.70 & 40.82 & 39.18 & 62.77 & $\%$ ar \\
\hline Volatile matter content & VM & 66.70 & 42.30 & 35.00 & 38.60 & $\% \mathrm{db}$ \\
\hline Ash content & A & 11.00 & 41.21 & 43.46 & 1.90 & $\% \mathrm{db}$ \\
\hline Higher heating value & $\mathrm{HHV}$ & 22.97 & 11.07 & 14.72 & 22.90 & $\mathrm{MJ} / \mathrm{kg}_{\mathrm{db}}$ \\
\hline Lower heating value ${ }^{2}$ & LHV & 11.59 & 5.22 & 7.66 & 7.08 & $\mathrm{MJ} / \mathrm{kg}_{\text {ar }}$ \\
\hline Carbon content & $\mathrm{C}$ & 51.00 & 27.8 & 31.86 & 61.54 & $\% \mathrm{db}$ \\
\hline Hydrogen content & $\mathrm{H}$ & 4.23 & 2.55 & 3.22 & 3.87 & $\% \mathrm{db}$ \\
\hline Nitrogen content & $\mathrm{N}$ & 0.94 & 0.56 & 0.74 & 0.61 & $\% \mathrm{db}$ \\
\hline Sulfur content & $\mathrm{S}$ & 0.87 & 0.49 & 1.14 & 0.50 & $\% \mathrm{db}$ \\
\hline Oxygen content ${ }^{3}$ & $\mathrm{O}$ & 42.96 & 27.39 & 19.58 & 31.58 & $\% \mathrm{db}$ \\
\hline
\end{tabular}

${ }^{1}$ Wet basis; ${ }^{2}$ Calculated using formula from EN 14918:2009; ${ }^{3}$ Calculated by difference; ar As received; $\mathrm{db}$ Dry basis.

Higher heating value was determined using an IKA C2000 basic bomb calorimeter (KA ${ }^{\circledR}$-Werke GmbH \& Co. KG, Janke \& Kunkel-Str. 10, 79219 Staufen, Germany), in compliance with the ISO 1928 norm. The isoperibolic method was used. Lower Heating Value was calculated using the moisture and hydrogen content. Ultimate analysis (Table 1) was performed using a Perkin Elmer 2400 analyser (331 Treble Cove Rd., Billerica, MA 01862, USA), according to Polish standard PKN-ISO/TS 12902:2007. Particle size distribution was determined using a set of calibrated sieves, compliant with ISO 3310-1.

\subsection{Test Rig—Toroidal Fluidized Bed Dryer}

During the suite of experiments described in this study, a toroidal fluidized bed rig was used to perform the drying. A diagram of the installation is shown in Figure 1. The test rig worked in a batch mode. A batch of approximately $2.5 \mathrm{~kg}$ of lignite was manually fed through a feeding hopper (E4 in Figure 1) during each test. The temperature of the drying air was maintained using two heaters with a temperature control system, each with a nominal power of $3 \mathrm{~kW}$ (E20 and E17 in Figure 1). Drying air was supplied by a blower (E3 in Figure 1) with a flow rate of the hot air of approximately $130 \mathrm{~m}^{3} / \mathrm{h}$ 
in order to obtain the same velocities for each of the tests. The flow rate was controlled using valves (E7 in Figure 1).

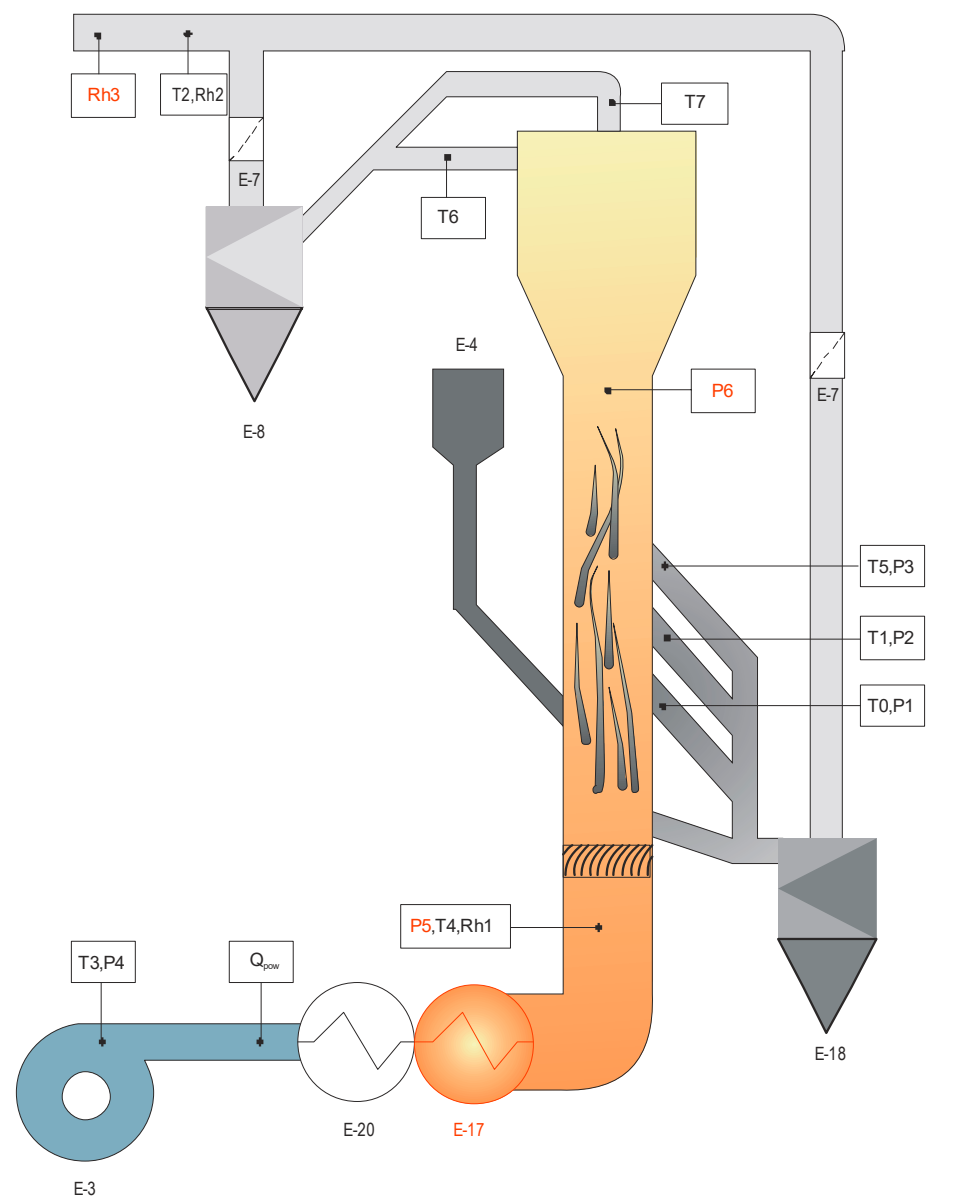

Figure 1. Torbed installation-diagram.

The toroidal bed dryer, shown in Figure 1, is a vertical cylindrical column closed at the top with an inverted truncated cone, wherein the heat exchange between the air and the dried material takes place directly. At the bottom of the fluidization chamber swirl blades are installed in order to create a vortex inside of the drying chamber.

During the suite of performed experiments the following parameters were measured: temperature, relative humidity, air flow rate and consumption of the electricity by each of the devices. Temperature and humidity sensors were installed at the inlet of the hot air to the dryer (T4 and Rh1 in Figure 1) and at the outlet of the installation ( $\mathrm{T} 2$ and $\mathrm{Rh} 2$ in Figure 1). Temperatures were measured using standard Pt1000 sensors, with specifications compliant with class A requirements defined in EN 60751. Relative humidity $(\mathrm{RH})$, which is the volume of water vapour in air divided by the maximum volume of water vapour, for a given temperature and pressure, was measured using HC1000-400 sensors and EE31transmitters with a working range of 0 up to $100 \% \mathrm{RH}$, temperature range falling between -40 up to $80{ }^{\circ} \mathrm{C}$, response time $<15 \mathrm{~s}$ and the accuracy reaching $2.4 \%$ (for the confidence interval of $95 \%$ ). Flow rate of the drying air was measured by a FCI ST-50 mass flow meter with an accuracy of $\pm 2 \%$ of the reading. Electrical load of the blower was measured with a Watt meter using a ND20 network meter produced by Lumel, with an accuracy of $\pm 1 \%$ of the measuring range $(1.65 \mathrm{~kW})$. All of the values were recorded with a sampling interval of $1 \mathrm{~s}$. 


\subsection{Zero-Dimensional Calculation Model of Drying—the Heat Balance of the Dryer}

A diagram of a zero dimensional model of the dryer, used for this study, is shown in Figure 2. The model describes a single stage dryer with an additional external drying agent heater. The model consists of a couple of sub-components. It was used for the calculation of the energy consumed by the dryer along the whole experiment, as well as for the calculation of the mass of removed water, based on the relative humidity of the air at the outlet of the dryer. According to the law of conservation of the energy, the sum of enthalpy entering the dryer must be equal to the sum of enthalpy leaving the dryer. The equation of the respective model of the dryer is:

$$
I_{1}+I_{2}=I_{3}+I_{4}+I_{5}
$$

where:

$I_{1}$ is the enthalpy of the drying air at the exit of the heat exchanger;

$I_{2}$ is the enthalpy of wet lignite entering the dryer, which could be separated into the enthalpy of water in the material and the enthalpy of dry matter;

$I_{3}$ is the enthalpy of the moist air leaving the dryer;

$I_{4}$ is the enthalpy of dried lignite leaving the dryer;

$I_{5}$ represents the loss of the enthalpy to the ambient by the casing of the dryer.

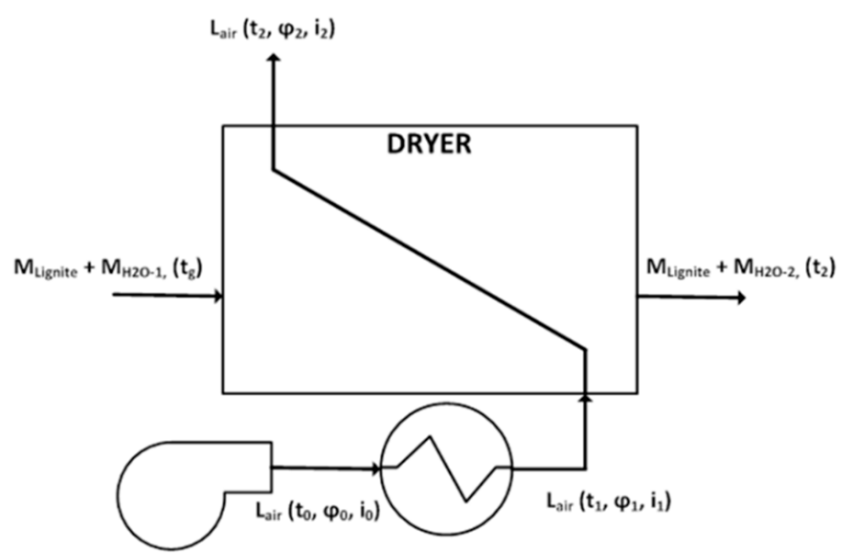

Figure 2. Diagram of a single stage dryer with additional external drying agent heater.

According to standard EN ISO 13788:2001 saturated vapour pressure was calculated:

$$
p_{\text {sat }}=610 \cdot e^{\frac{17,269 \cdot T}{33,5+T}} \text { for } T \geq 0{ }^{\circ} \mathrm{C}
$$

where:

$p_{\text {sat }}$-saturated vapour pressure, $\mathrm{Pa}$;

T-temperature, ${ }^{\circ} \mathrm{C}$.

Absolute moisture content in the air, taking into account the measured relative humidity:

$$
X=0.622 \frac{\varphi \cdot p_{\text {sat }}}{100 \cdot p-\varphi \cdot p_{\text {sat }}}
$$

where:

$X$-absolute moisture content in the air, $\mathrm{kg} \cdot \mathrm{m}^{-3}$ (dry air);

$\varphi$-air relative humidity, $\%$; 
$p$-humid (ambient) air pressure, Pa;

$p_{\text {sat }}$-saturated vapour pressure, $\mathrm{Pa}$.

The increase of moisture content in the air corresponding to the loss of moisture content in the lignite:

$$
\Delta X=0.622\left(\frac{\varphi_{2} \cdot p_{\text {sat } 2}}{100 \cdot p-\varphi_{2} \cdot p_{\text {sat } 2}}-\frac{\varphi_{0} \cdot p_{\text {sat } 0}}{100 \cdot p-\varphi_{0} \cdot p_{\text {sat } 0}}\right)
$$

where:

$\Delta X$ —increase of the absolute moisture of the drying agent (air), $\mathrm{kg} \cdot \mathrm{m}^{-3}$;

The amount of water removed from the lignite in a given time interval corresponds to the difference in the amount of water contained in the air at the inlet and outlet of the dryer. The instantaneous value of the loss of water by the lignite (between two moments $t_{1}$ and $t_{2}$ ) are determined from the formula:

$$
M_{\text {evap }}=\frac{\Delta X}{\rho_{\text {dry }}} \cdot V_{\text {wet }} \cdot \rho_{\text {wet }}\left(t_{2}-t_{1}\right)
$$

where:

$M_{\text {evap }}$-loss of water in the coal, $\mathrm{kg}$;

$\Delta X$-increase of the absolute moisture of the drying agent (air), $\mathrm{kg} \cdot \mathrm{m}^{-3}$;

$\rho_{\text {wet }}$-density of the wet air, $\mathrm{kg} \cdot \mathrm{m}^{-3}$;

$\rho_{\text {dry }}$-density of the dry air, $\mathrm{kg} \cdot \mathrm{m}^{-3}$;

$V_{\text {wet }}$-the air flow at the inlet of the dryer, $\mathrm{m}^{3} \cdot \mathrm{h}^{-1}$.

\subsection{Test Method and Schedule}

Drying tests were performed on the stand presented in Figure 1 for the stream of hot air of $130 \mathrm{~m}^{3} \cdot \mathrm{h}^{-1}$ at temperatures of $35^{\circ} \mathrm{C}, 50{ }^{\circ} \mathrm{C}, 60^{\circ} \mathrm{C}, 70{ }^{\circ} \mathrm{C}$ and $80^{\circ} \mathrm{C}$. Tests were carried out until the change of the humidity of the drying air, between the inlet and the outlet of the dryer, was deemed to be insignificant (see Figure 3). When that point was reached, the lignite had achieved equilibrium with the incoming dry air, thus further drying was not possible. Reaching this state by the dryer is referred to as reaching the final moisture content and the time to reach this value is called the drying time. With the increase of the drying agent temperature a lower final moisture content was typically reached within relatively shorter drying times. Figure 3 shows the measured and recorded values during the drying testing of Polish lignite at the temperature of $50{ }^{\circ} \mathrm{C}$. The graph shows only those parameters that are used to calculate the drying kinetics and to determine the energy consumption of the drying process, i.e., air flow, temperature and humidity on the dryer inlet and outlet).

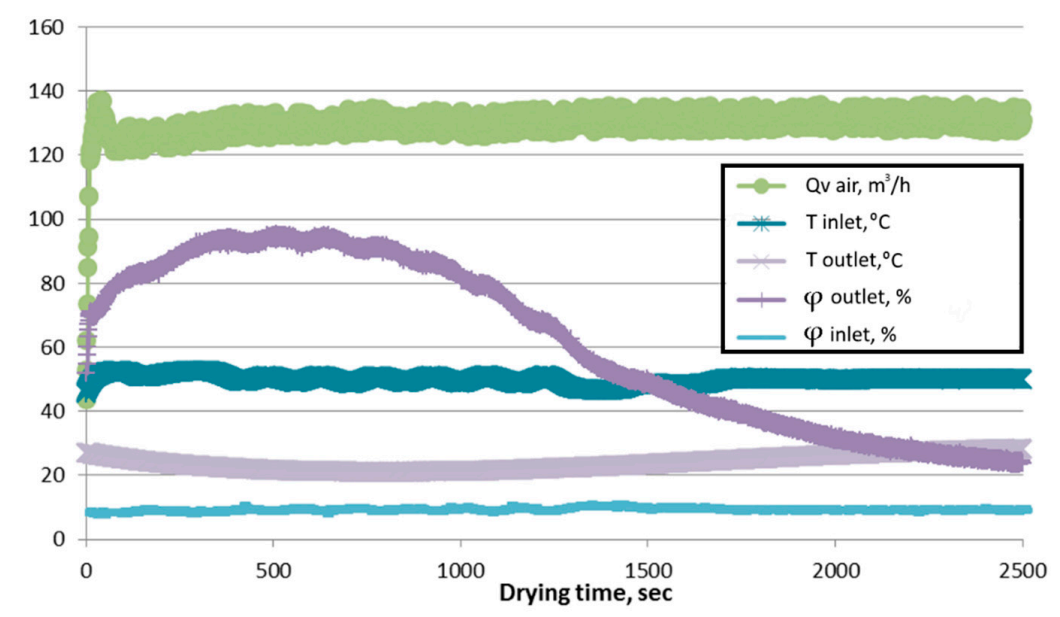

Figure 3. An example of the drying test for Polish lignite at the temperature of $50{ }^{\circ} \mathrm{C}$. 


\section{Results}

Drying tests for the torbed dryer were performed, using lignites from Poland, Greece, Romania and Australia. Results of the proximate and elemental analysis are presented in Table 1. Figure 4 presents the particle size distributions, which are averages for all the tests, performed within the whole range of temperatures.

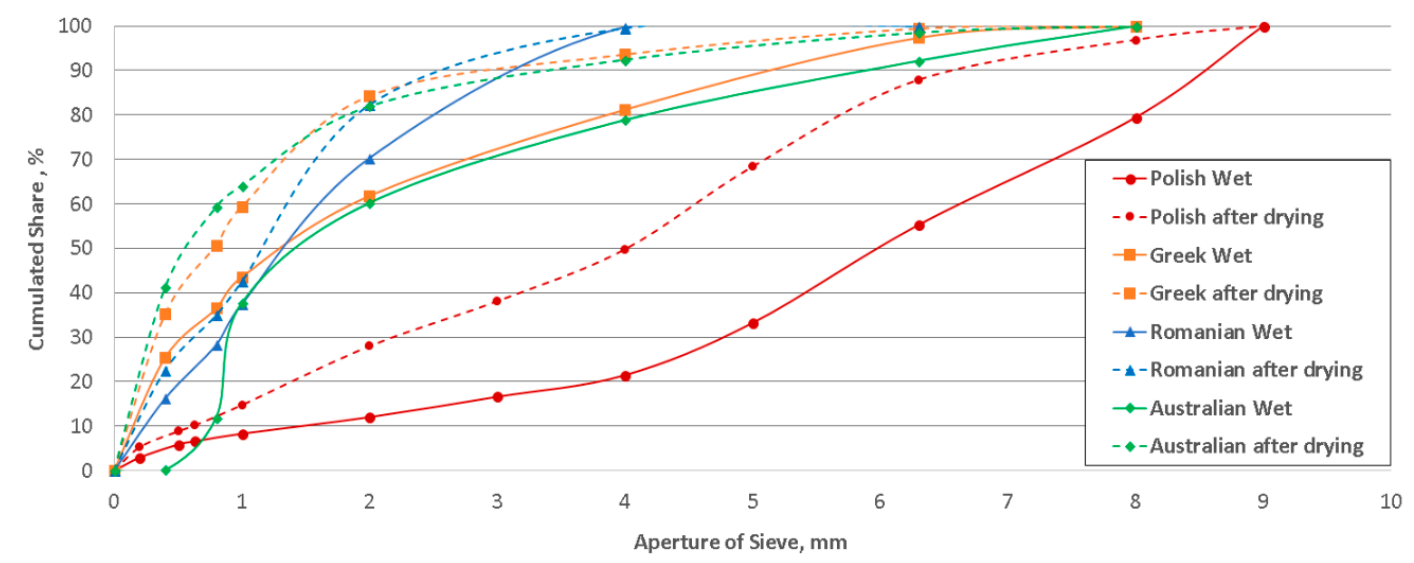

Figure 4. Particle size distribution of lignite of various origin before and after drying in the Torbed installation.

Figure 5 compares median particle size for wet and dry lignite and compares results obtained in this study with results published in another study on drying in a fluidized bed. It depicts respective changes of median particle size $\left(d_{50}\right)$ for each of the lignites due to the performed drying. It depicts the difference between Polish lignite and other lignites used for this study. It also shows that changes in the median particle size varied between the lignites. Changes in $\mathrm{d}_{50}$ diameters varied between different lignites (Figure 5), with the relative change being the highest for Australian lignite and lowest for Romanian lignite.

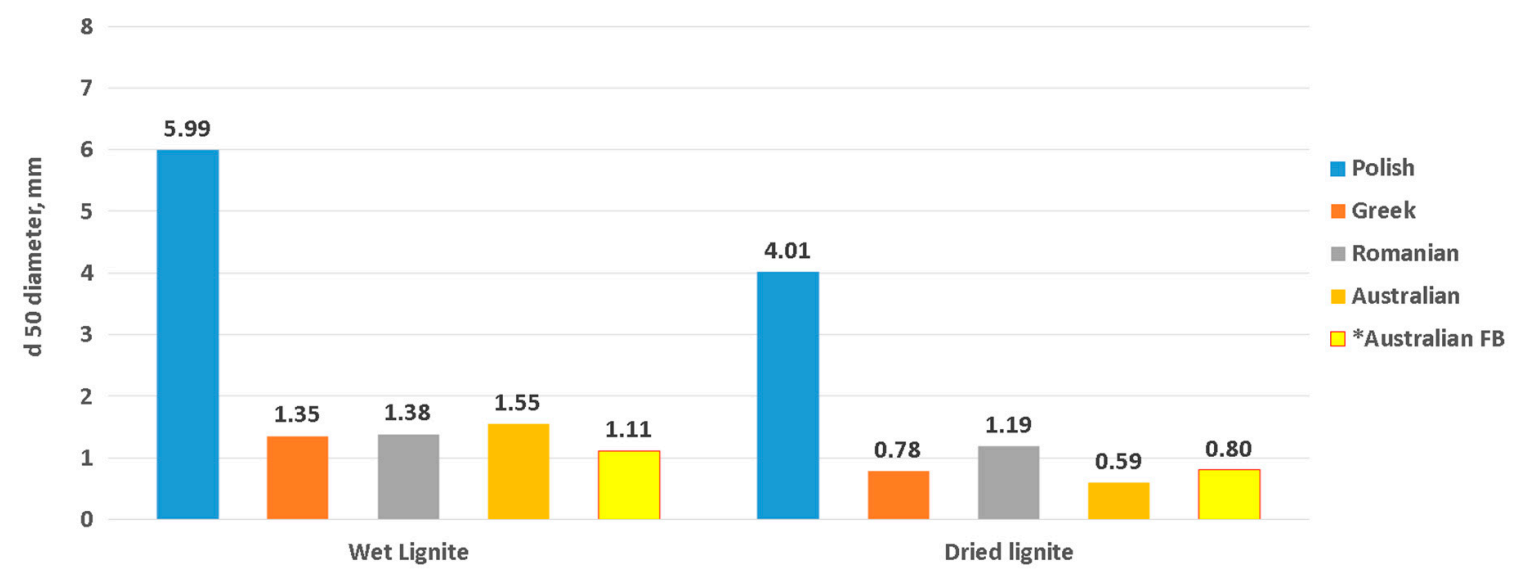

Figure 5. Median particle size $\left(d_{50}\right)$ for wet and dried lignite ( ${ }^{*}$ results of Stokie et al. [19] for comparison).

Taking into consideration the principle of operation of the toroidal bed dryer, it seems plausible to expect that the attrition of the particles could be also considered as one of the factors influencing the change of the particle size distribution after drying. Evidence of the weakened, cracked structure of the particles dried in the toroidal bed, is demonstrated in SEM pictures shown in Figure 8. 
Figures 6 and 7 show examples of different distributions of moisture content between particles of different sizes. These two figures clearly demonstrate that the fine particles were prematurely entrained out of the toroidal bed. This resulted in higher moisture content of the entrained fines, at the outlet of the dryer. Figure 8 shows a difference in terms of the surface of two lignite particles, one dried in a muffle furnace at $100{ }^{\circ} \mathrm{C}$ and another dried in toroidal bed at $50^{\circ} \mathrm{C}$.

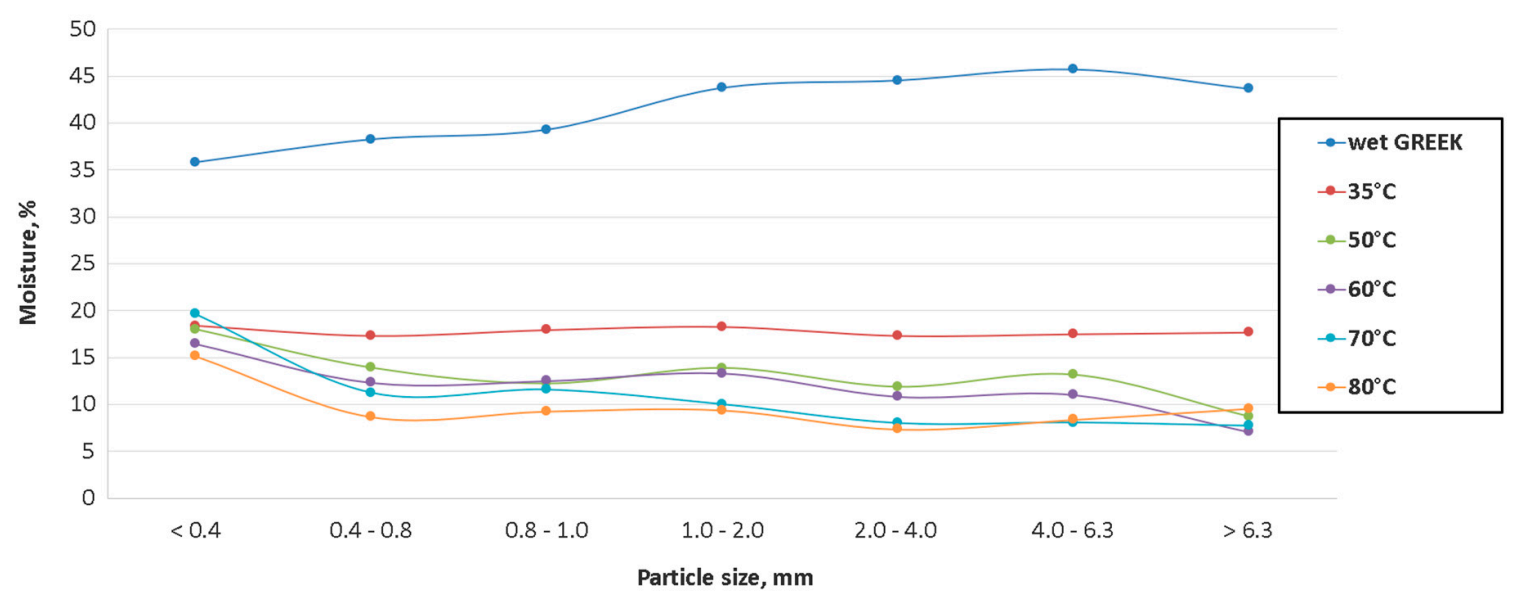

Figure 6. Difference between the moisture content of particles of different sizes for wet and dried lignite-an example of Greek lignite for various temperatures of the drying process.

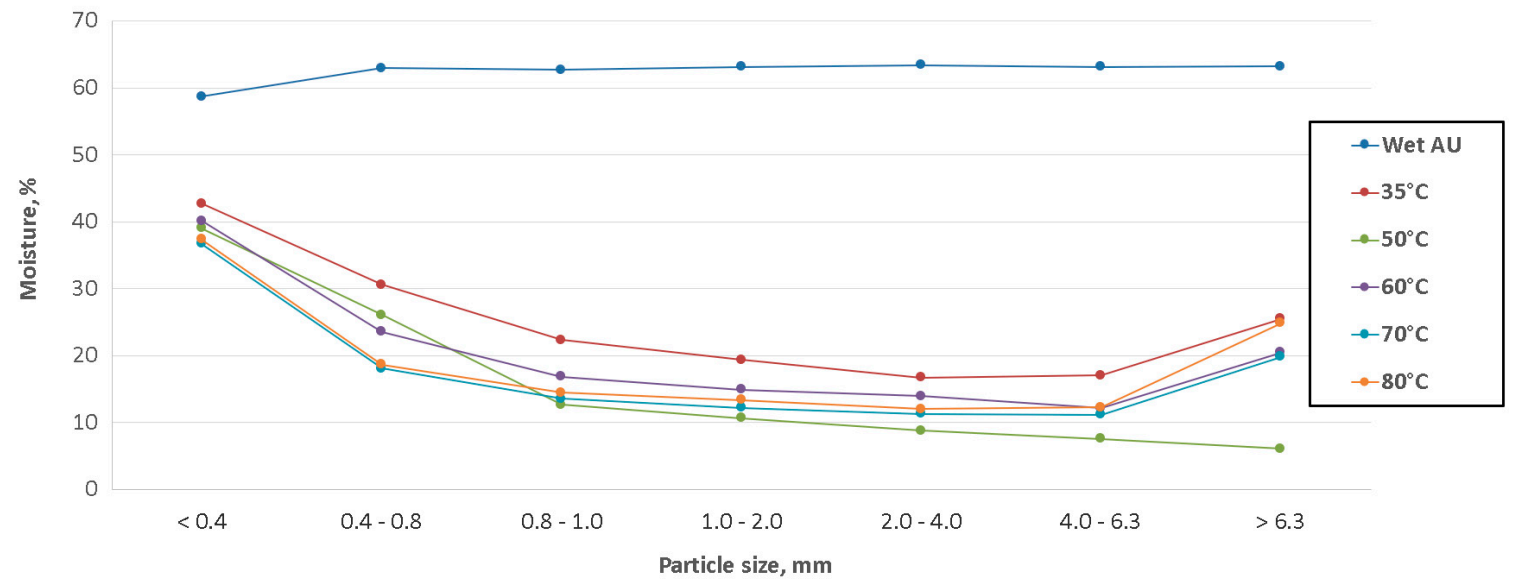

Figure 7. Difference between the moisture content of particles of different sizes for wet and dried lignite-an example of Australian lignite for various temperatures of the drying process. Drying kinetics, for Sieniawa lignite, in the torbed installation and total energy consumption per kg of removed water are presented in Figures 9 and 10, respectively. Figure 9 shows curves representing the loss of moisture for the lignite from Sieniawa mine. Below the final moisture content of $15 \%$ a significant reduction in drying rate occurs for all temperatures of the drying agent. This value is called critical moisture content and depends mostly on the structure of the lignite and its chemistry. This is a useful indicator that allows to determine the proportion of the water held physically within the structure of the lignite through capillary forces and the amount of water bound chemically, for example by weak hydrogen bonds with $\mathrm{OH}$ functional groups. The parameter itself does not give a sharp cut away point and depends slightly on the drying conditions. 


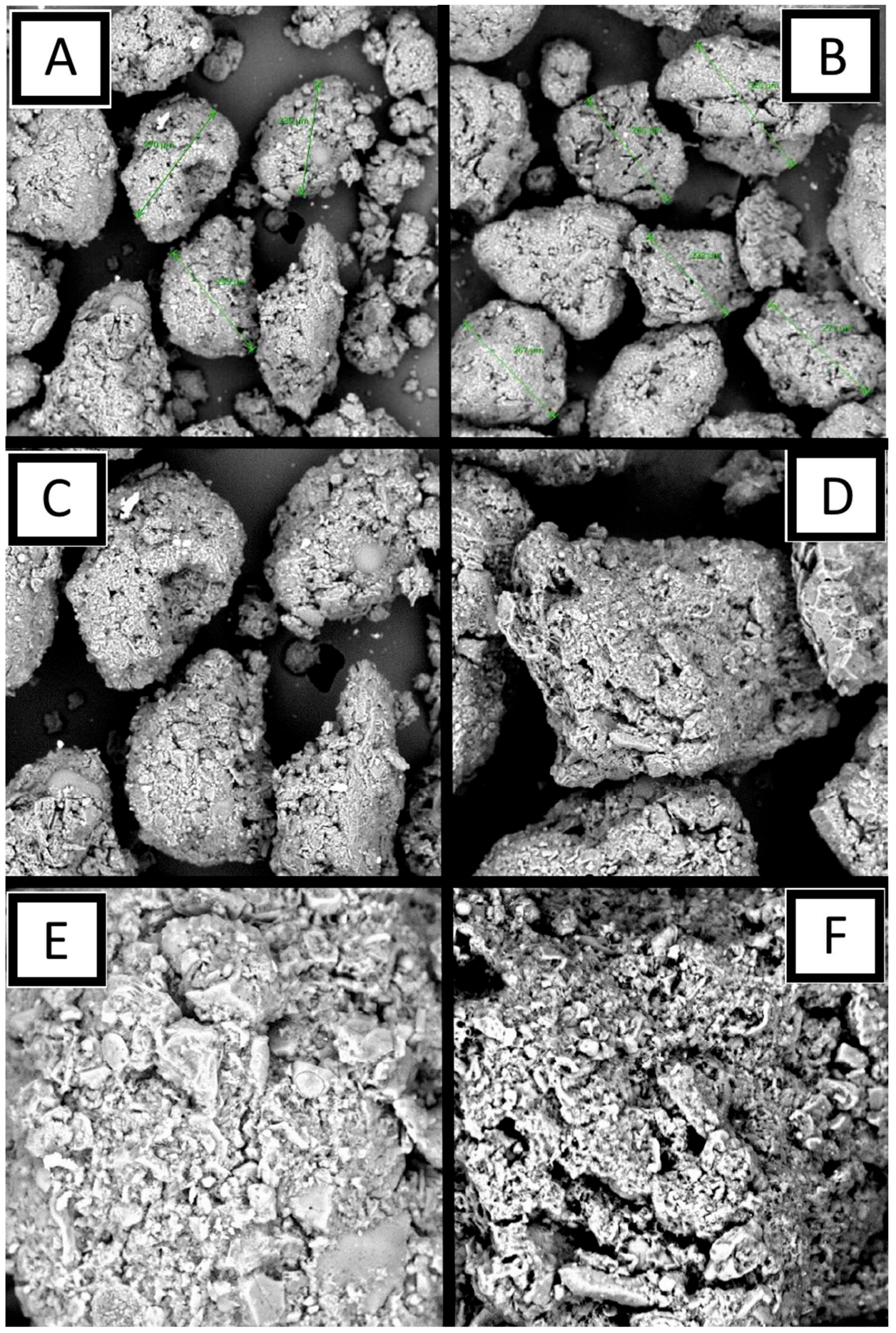

Figure 8. SEM pictures of the Australian lignite dried in a laboratory muffle furnace at $100{ }^{\circ} \mathrm{C}(\mathbf{A}, \mathbf{C}, \mathbf{E})$ and torbed dryer at $50^{\circ} \mathrm{C}(\mathbf{B}, \mathbf{D}, \mathbf{F})$ - magnifications $\times 300(\mathbf{A}, \mathbf{B}), \times 750(\mathbf{C}, \mathbf{D})$ and $\times 1500(\mathbf{E}, \mathbf{F})$; sample sieved through screen with aperture of $0.4 \mathrm{~mm}$. 


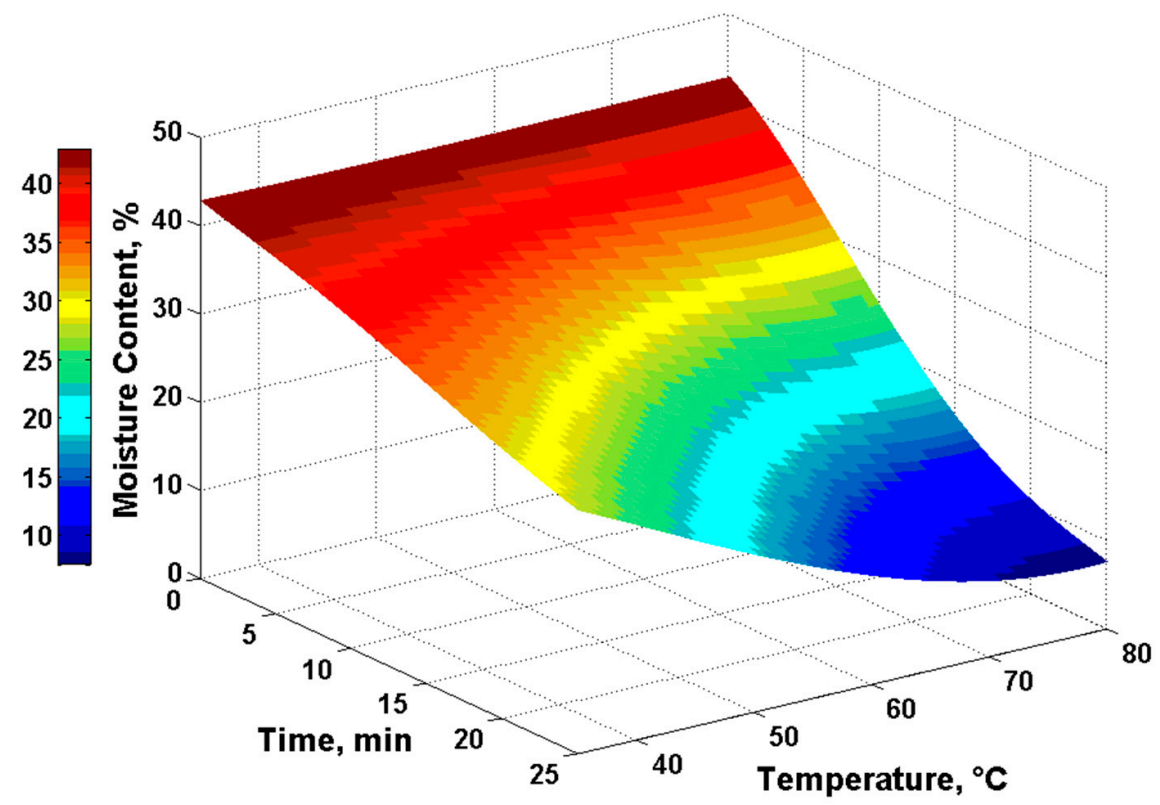

Figure 9. Drying kinetics in the torbed installation for Polish lignite.

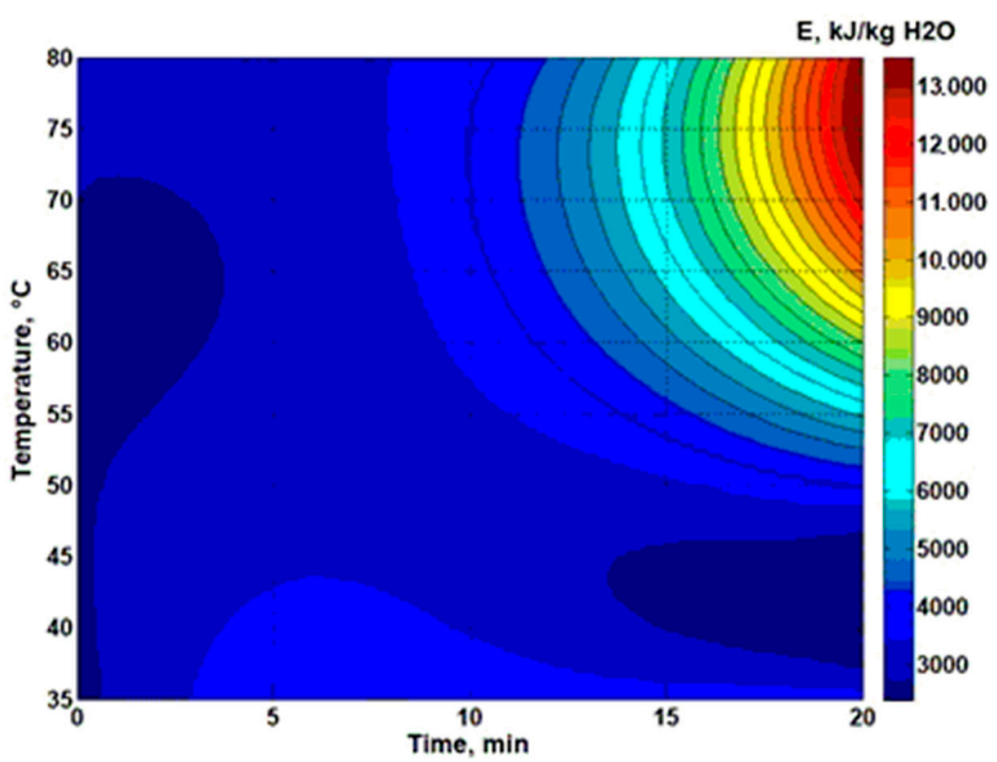

Figure 10. Total energy consumption per $\mathrm{kg}$ of removed water during drying of Polish lignite in the torbed installation.

In a similar manner drying kinetics, for Greek lignite, in the torbed installation and total energy consumption per $\mathrm{kg}$ of removed water are presented in Figures 11 and 12, respectively. Greek lignite required much higher residence times in order to reach the same moisture content, in comparison to Polish lignite. Specific drying energy, shown in Figure 12, was similar to the levels registered for Polish lignite. However, a rapid increase of the specific energy consumption started much sooner for the Greek lignite. Taking into the account the almost identical initial moisture content of Polish and Greek lignite it seems plausible to conclude that the latter exhibits a higher critical moisture content-i.e., its drying is more difficult. 


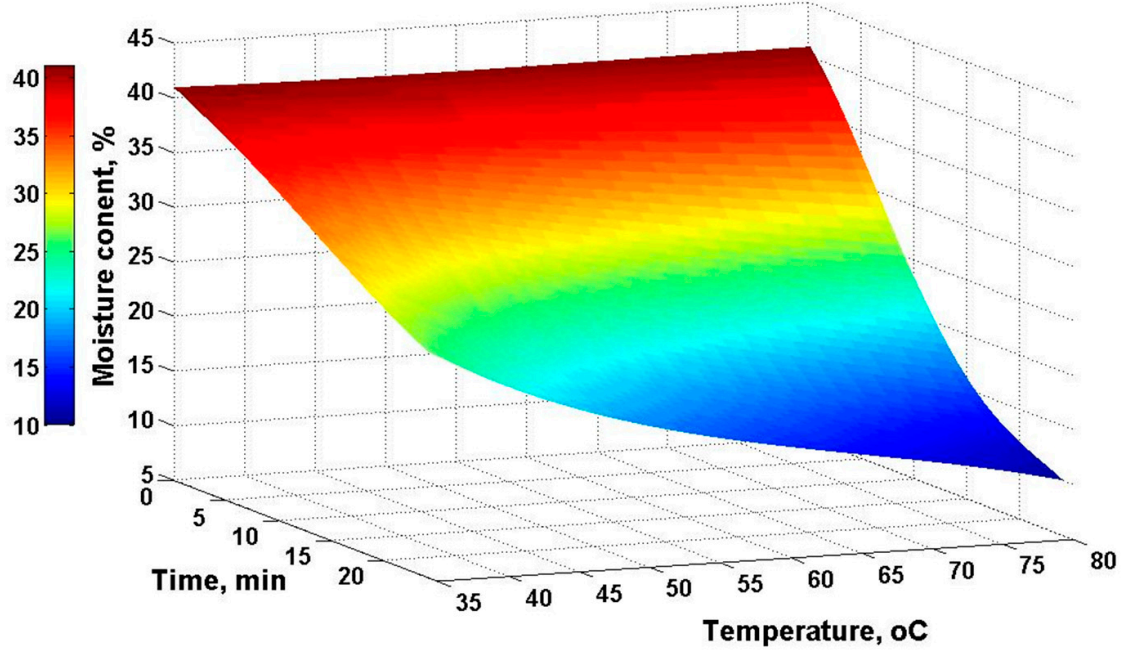

Figure 11. Drying kinetics in the torbed installation for Greek lignite.

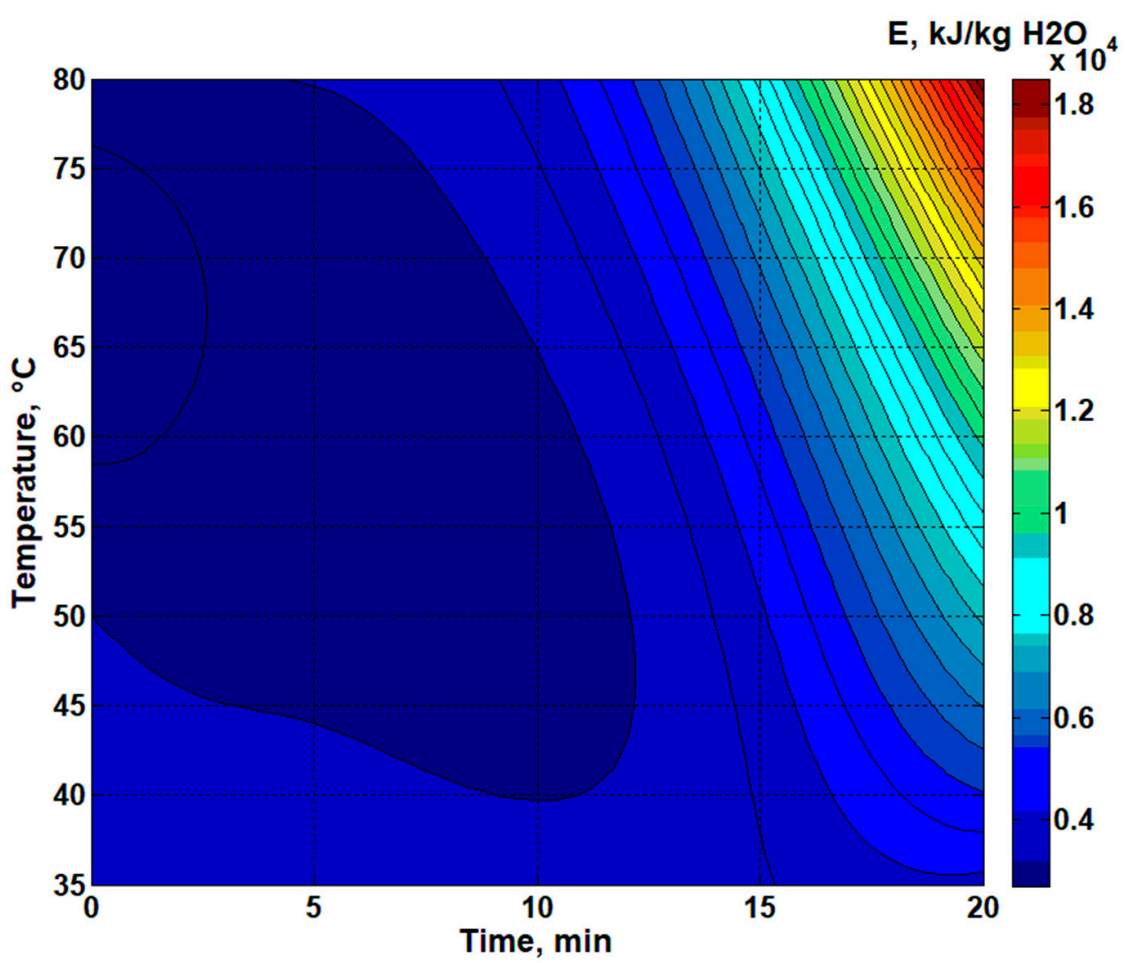

Figure 12. Total energy consumption per $\mathrm{kg}$ of removed water during drying of the Greek lignite in the torbed installation.

Figures 13 and 14 show, respectively, the drying kinetics in the torbed installation and total energy consumption per $\mathrm{kg}$ of removed water, for Romanian lignite. In terms of its drying kinetics Romanian lignite (Figure 13) can be considered an intermediate type that dries faster in comparison to Greek lignite and slower when compared to Polish lignite. The sample of the Romanian lignite exhibited the lowest initial moisture content of all the tested samples. In terms of the specific energy consumption, Romanian lignite demonstrated a behaviour similar to the Greek lignite with respect to the time when the sharp increase started (Figure 14). Drying kinetics, in the torbed installation and total energy consumption per kg of removed water, for Australian lignite are presented in Figures 15 and 16. 


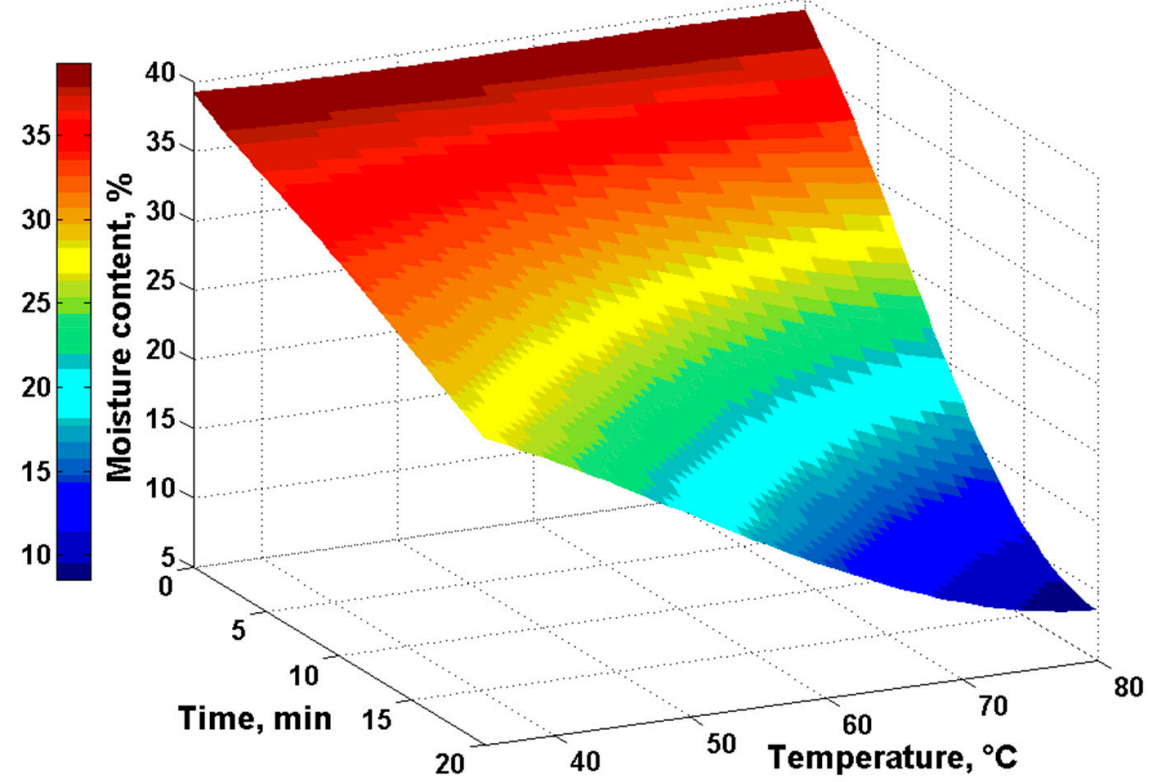

Figure 13. Drying kinetics in the torbed installation for Romanian lignite.

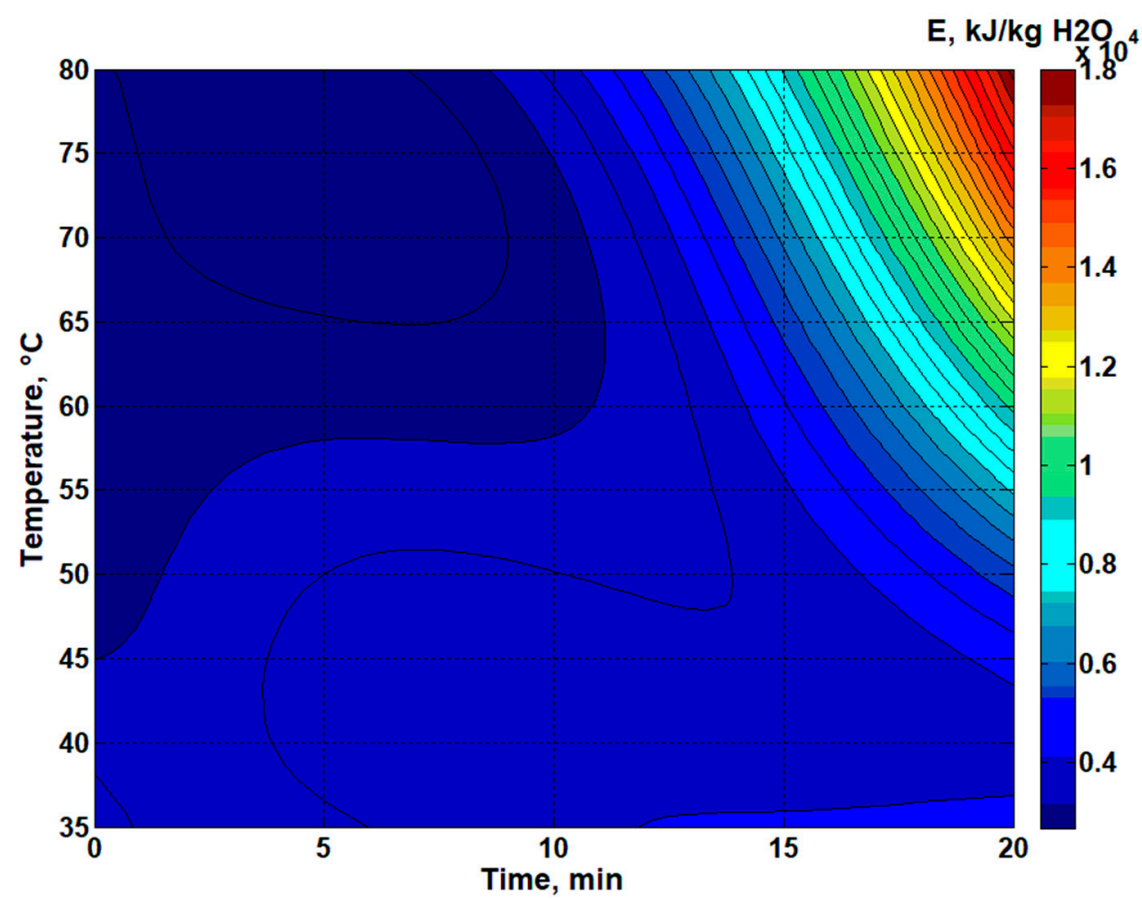

Figure 14. The energy consumption per kg of removed water during drying of the Romanian lignite in the torbed installation.

Data presented in Figure 17 gives an indication of the required residence time necessary to achieve the moisture content of $20 \%$, with the exception of Australian lignite. In that case the drying time required to obtain the final moisture content of $35 \%$ is shown. Australian lignite usually needed substantially higher residence times in comparison to other samples. 


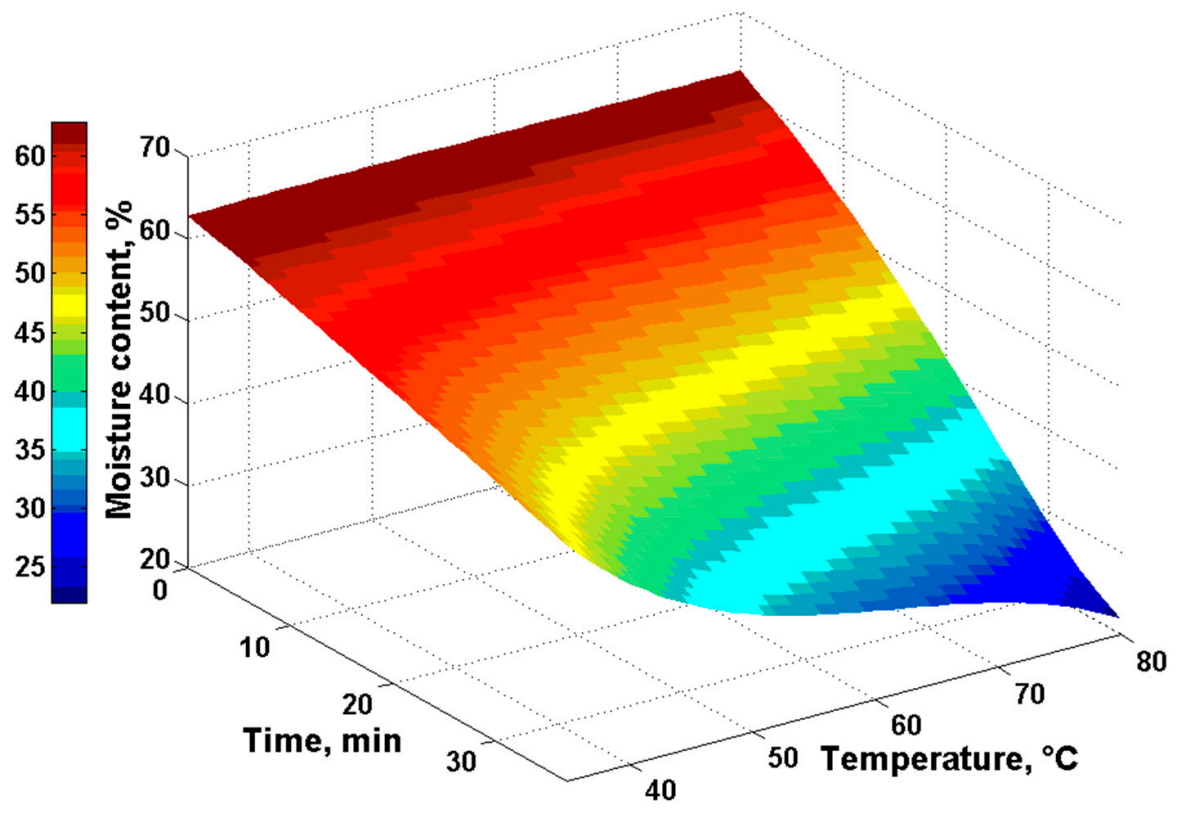

Figure 15. Drying kinetics in the torbed installation for Australian lignite.

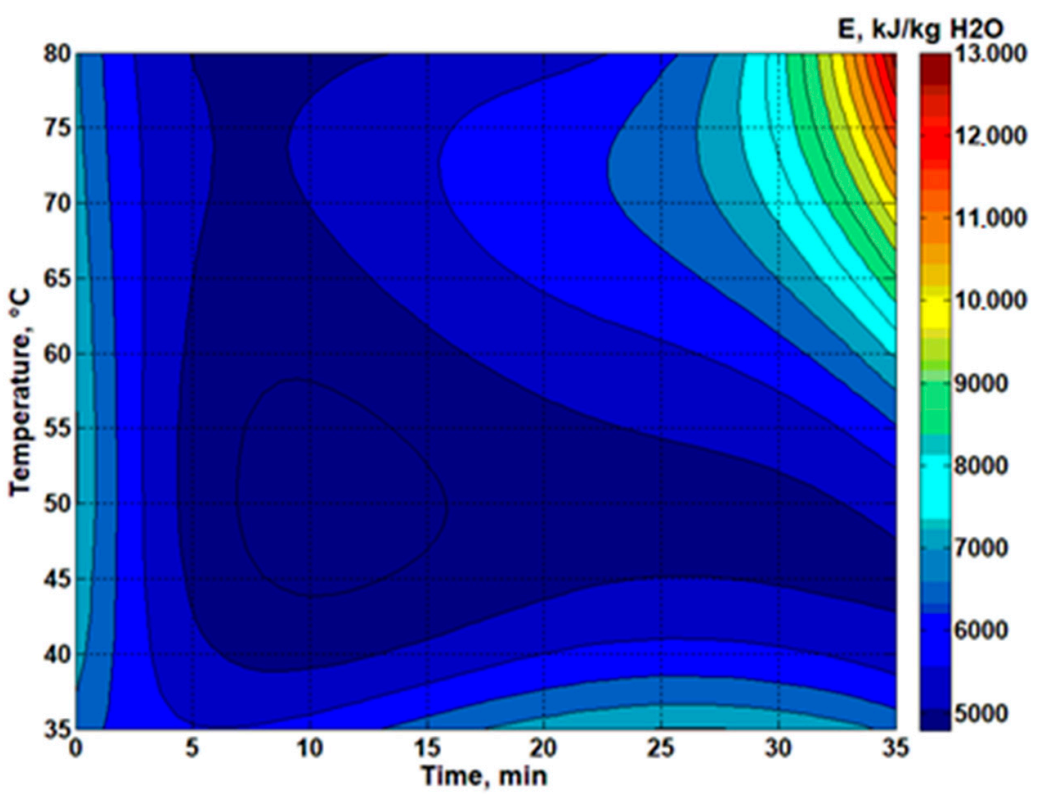

Figure 16. The energy consumption per $\mathrm{kg}$ of removed water during drying of the Australian lignite in the torbed installation.

Figure 18 summarizes average energy consumption required to achieve moisture content of $20 \%$ for tested types of lignite in the torbed installation (with exception for Australian lignite, for which the energy to dry up to $35 \%$ for moisture content is given). Data presented in Figure 18 gives a bit of an insight that could help in the optimisation of the drying process for a lignite dryer based on the toroidal bed design. It shows an average total energy consumption per $\mathrm{kg}$ of water removed during drying process. An average is taken, as the consumption of the energy by the whole process is of interest from practical point of view. Australian lignite was unlike the other lignites tested, with its initial moisture content close to $65 \%$ and an exceptionally low ash content, slightly lower than $2 \%$ (see Table 1). This lignite proved to be the most difficult to dry (see Figure 15) and required the longest time in order to reach a final moisture content comparable to those achieved by the other lignites. Overall, the final moisture content (corresponding to the value of equilibrium moisture at temperature of drying air) for each of the drying temperatures was the highest in case of Australian lignite. 


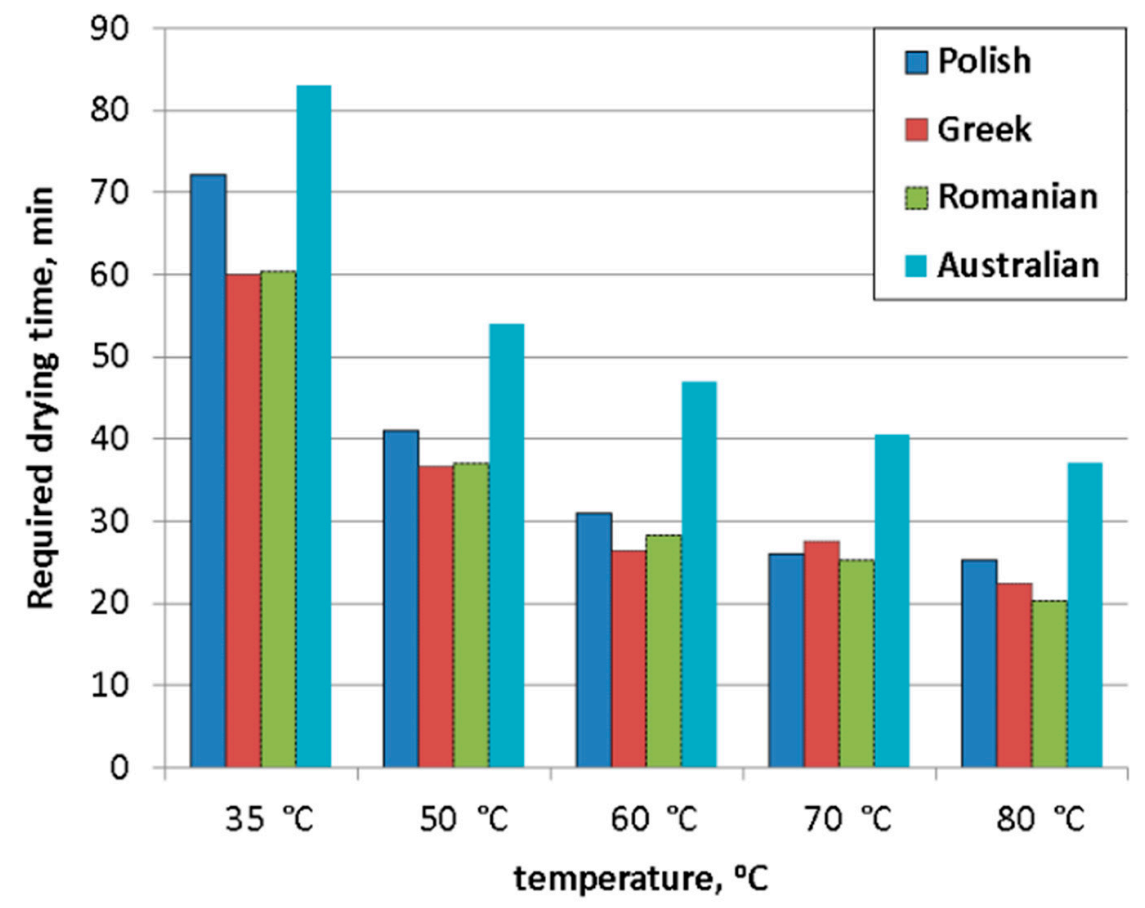

Figure 17. Drying time required to achieve the final moisture content for tested lignites of various origins in the torbed installation.

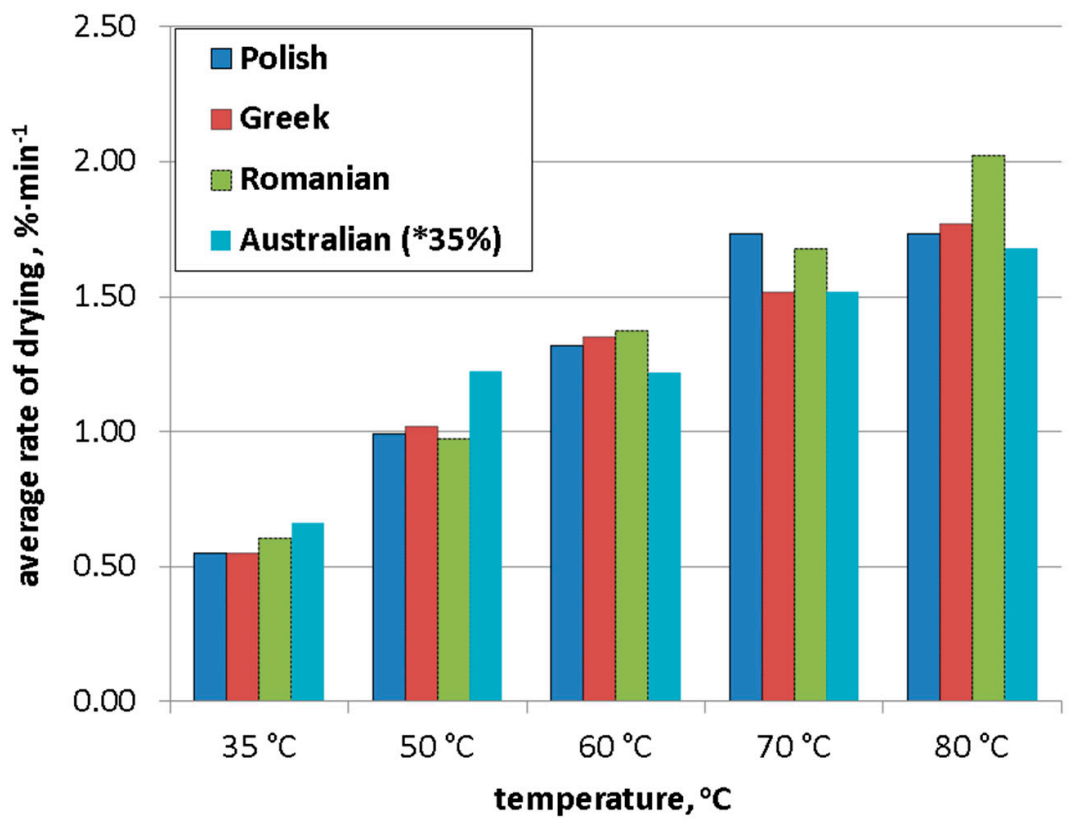

Figure 18. Average energy consumption required to achieve moisture content of $20 \%$ for tested types of lignite in the torbed installation (* energy consumption for Australian lignite is given for a final moisture content of $35 \%$, due to a relatively high initial moisture content).

\section{Discussion}

Drying of the lignite, in the toroidal bed dryer, is followed by the reduction of individual particles sizes, resulting in a significant change of the size distribution. It is clear, looking at the Figure 4 , that a certain amount of finer particles is being produced during the drying process. Results obtained by Stokie et al. for the same type of lignite were slightly different, i.e., attrition being much lower (Figure 5). In the fluidized bed, according to Stokie et al. [19], the effect of scale was significant, as 
experiments with $10 \mathrm{~g}$ sample, resulted in no attrition, whereas experiments with a sample of $3 \mathrm{~kg}$ showed some differences between $d_{50}$ of wet and dried lignite samples (Figure 5). As the sample size used for this study, was similar $(2.5 \mathrm{~kg})$ it can be stated, that the effect of the attrition during drying in the toroidal bed is much higher, in comparison with a typical fluidized bed. This can be used as a confirmation of higher degree of turbulence taking place in the toroidal bed.

Looking at the examples of the Greek and Australian lignite effect of drying (Figures 6 and 7, respectively) it is relatively easy to observe that generally fine particles exhibit relatively higher moisture content after drying in the toroidal bed. It seems plausible to assume that this is due to the entrainment of the fine particles out of the toroidal bed, when the density of the particle decreases with drying, thus lowering the terminal velocity of the particular particle. The highest difference was obtained for the Australian lignite, which also had much lower ash content, in comparison to the other types of lignite. It seems plausible to presume that low ash content corresponds with lower true density of the particles. The observed entrainment decreased the residence time of the particles, which impeded the drying of fine particles. Obviously low enough temperature of the drying agent in the toroidal bed, decreased by evaporation, decreases its velocity enough to minimize the loss of wet fines, which is clearly demonstrated at the Figure 7.

In some of the cases (Figure 7) also particles of Australian lignite with a diameter relatively close to the top size exhibited a moisture content above the average for the whole sample. This on the other hand should be attributed to the insufficient drying time, which was a consequence of the significantly high initial moisture content of the lignite. In the case of coarse particles higher residence time would be required to achieve the moisture content similar to that of the particles of average size.

Another factor playing an important role in the change of the particle size distribution of the dried sample is the shrinkage of the particles during drying process-as already depicted in Figure 4. That behaviour could cause bigger particles shrink, thus increasing the total share of fine particles when the cumulative size distribution is considered. On the other hand, it is reasonable to expect the particle shrinkage to counterbalance the aforementioned effect of the premature entrainment of fine particles, due to increased density for the same dry mass of the particle, caused by decreased volume of the particle.

Cracks of the structure are clearly visible in SEM pictures with higher magnifications $(\times 1500)$. These cracks did not appear when the same sample was dried in a laboratory muffle furnace (on trays). Therefore, it seems plausible to draw the conclusion that the cracks were not caused by the evaporation of the water itself, but rather by the working principle of the bed. Thus attrition and falling apart of the particles could be considered as one of the factors influencing the change in the particle size distribution of the dried lignite. Due to the aforementioned weakening of the structure of dried particles, it can be reasonably expected that the grindability of dried lignite would surely increase in comparison to the corresponding wet feedstock. Moreover, the degree of changes between lignites of different origins varied considerably for the same drying conditions (Figure 4), which implies some structural differences between all the different types of lignite within the scope of this study. However, negative effects should not be overlooked, as the production of the additional amounts of fines might bring the mixture of drying agent and dried lignite within the explosive concentration limit, which in combination with the high friction could cause a static discharge and explosion. Therefore, much of the designer's attention should be directed towards grounding the parts in dryer and ducting that are in contact with the bed of material entrained by the drying agent. Moreover, solid load (the proportion of the volumetric air flow and the mass flow rate of the feedstock) should be considered carefully in order to achieve a concentration of fines below the lower explosive limit (LEL) of the particular feedstock.

Specific energy consumed for removing a kilogram of water, depicted in Figure 10, consists of the heat needed to heat up the drying agent (air) from ambient to the drying temperature and the electricity consumed by the blower. The latter changes slightly due to the decreased pressure drop through the toroidal bed, caused by the decreased mass, due to the gradual drying. However, the major change of the specific drying energy is caused by the fact that the same thermal energy input of air 
is consumed by a smaller amount of moisture removed from the material-i.e., the mass loss due to the moisture removal is gradually smaller (smaller $\mathrm{dm} / \mathrm{dt}$ ). Similar information can be obtained from Figure 3, where the relative humidity of the drying agent at the outlet of the dryer exhibits clear maximum and starts decreasing past that point.

The total specific energy for drying can be significantly lower in the case of recovery of heat from outlet air, especially for higher air temperature input. Observations are similar for all the tested lignite samples. Nonetheless, the results themselves are different, despite sharing a common pattern. These differences suggest structural differences between lignites of different origins.

One interesting phenomenon was a higher energy consumption for drying of Romanian lignite at $35^{\circ} \mathrm{C}$ and $50^{\circ} \mathrm{C}$. This can be explained by a relatively high resistance of the bed in comparison with other lignites. Moreover, the change in the particle size distribution between the wet and dried Romanian lignite is one of the lowest among all the lignite (see Figure 4). This might suggest that attrition gets more significant only after drying at temperatures higher than $50{ }^{\circ} \mathrm{C}$. Comparing it to the energy consumption for drying of Greek lignite (Figure 12) it is reasonable to conclude that the attrition threshold is higher in the case of Romanian lignite (Figure 4). In case of the Greek lignite only the test performed at $35^{\circ} \mathrm{C}$ yielded higher energy consumption when compared to drying of the same lignite in higher temperatures. In case of both sorts of lignite, structural differences seem to be the only plausible explanation of this behaviour. Moreover, such a behaviour was not observed during trials performed with Polish lignite. A common indicator of the structural similarity might be the ash content as it was similar for both Greek and Romanian lignite (approx. 40\%), which was different to both Polish lignite (ash content approx. 20\% for both).

Proper selection of the optimum drying parameters should be selected for each type of lignite individually, due to its unique properties, determined by its structure. Moreover, first estimate of the drying parameters is also of crucial importance in terms of the proper sizing of the dryer that should meet the required expectations in terms of its capacity and the quality of the product, defined by its required moisture content of the dried lignite. Summary of the data is presented in Figures 17 and 18. The obtained results clearly show that the change in required residence time loses significance for drying temperatures higher than $60{ }^{\circ} \mathrm{C}$, which implies that higher drying temperatures would not allow to any significant gain in terms of the downsizing of the drying equipment. The data could also be used for the optimisation of the existing unit, under the assumption that the similar test procedure would be applied to the particular lignite. Presented data could also be helpful in managing the expectations as to the moisture content that can be achieved in practice for each of the lignites individually. The suite of performed tests allowed us to determine that for most of the lignites feasible moisture content that can be achieved after drying is $20 \%$. The only exception is the lignite from Australia, in case of which the feasible moisture content after drying was assessed to be $35 \%$. Lignite from Sieniawa was selected as an overall representative sample for Polish lignites.

High initial moisture content and physical structure of Australian lignite posed practical difficulties, due to the lumps of bed material sticking to the walls and falling back to the bed due to attrition, which distorted the measurements of the specific energy consumption (see Figure 16). The lumps that stuck to the walls of the dryer at some point fell down, probably due to the attrition, caused by the toroidal bed. Nonetheless, it can be stated that the specific energy consumption for drying of the Australian lignite, was much higher than for all the other types of lignite for a final moisture in the order of $10 \%$.

Overall all the lignites, except the Australian one, exhibit similar required residence times, which indicates that the required size of the dryer would not be significantly different in these cases. For the case of drying of Polish lignite at $35^{\circ} \mathrm{C}$, the required time is also significantly different, in comparison to Romanian and Greek lignite. For Polish lignite, the lignite drying time at $35^{\circ} \mathrm{C}$ was 73 min reaching a final moisture content of $12.9 \%$. Drying at $70{ }^{\circ} \mathrm{C}$ and $80{ }^{\circ} \mathrm{C}$ resulted in a significantly shorter drying time (about $28 \mathrm{~min}$ ) and allowed to achieve greater degree of drying-reaching a final moisture below $8 \%$. 
Looking at Figure 18 makes it clear that for all the lignites, except the Australian one, a drying temperature of $60^{\circ} \mathrm{C}$ is the most beneficial, from an energy optimisation perspective, as it allows one to minimize the energy consumption. The optimum drying temperature for the Australian lignite is clearly $50{ }^{\circ} \mathrm{C}$. It seems important to note that the specific energy consumption for Romanian lignite still decreases slightly for drying temperatures higher than $60^{\circ} \mathrm{C}$. However, the significance is negligible, therefore the lowest feasible drying temperature is advised in that case. The reason for that would not be connected directly to the dryer itself, but rather to the heat source. Assuming that the drying would take place at the source of the lignite, where the power plant is also located, one of the possible heat sources for the heated air would be the flue gases after the air-pre heater. Lower temperature of the drying air would therefore allow higher $\Delta t$ for the heat exchanger preheating the drying air. Thus smaller heat exchange surface would be required, implying a lower cost of such a device. Moreover, if temperature below the dew point of the flue gases could be achieved, condensing heat exchanger would allow to recover additional heat from the flue gases.

One of the most important parameters is the energy consumption per $\mathrm{kg}$ of moisture removed from the material. Energy consumption is very important in terms of economy of the drying process. Its value will depend on the availability of heat for drying and the possibility of using waste heat. Residence time is also important, as it determines the size of the equipment, which in turn has a profound influence on total cost of the dryer.

There seems to be no rule of thumb as to the best possible type of dryer that could be picked in case of any type of lignite. In the choice of the most suitable type of the dryer and subsequent choice of the optimum process parameters, multiple factors have to be taken into account. In terms of drying in the toroidal bed, one of the factors determining the optimum process parameters is the particle size distribution of the feedstock. Concerns are valid both from the performance and health \& safety point of view. One of the key aspects is the flow rate of the drying agent and ratio of the drying agent to the amount of dried solids. Drying with too low volumetric flow rate of the drying agent will determine relatively high residence time needed, which could result in a higher capex due to the bigger dryer. On the other hand too high volumetric flow rate of the drying agent can cause nonuniform drying due to a premature entrainment of fines out of the bed. Moreover, due to the nature of the toroidal bed, increased friction may increase generation of fines, thus amplifying the process. On top of that additional generation of fines might potentially pose a safety issue, if enough fines are generated to obtain an explosive atmosphere, especially taking into consideration friction that can potentially induce a static discharge (source of ignition). Fortunately, in this case water vapours, carried away by the drying air, are a natural inhibitor. However, this aspect has to be considered for each of the cases individually, as different lignites exhibited different behaviour in terms of the generation of fines, during drying. Proper grounding of the device, should be implemented in any case as a precautionary measure against a static discharge. Moreover, proper choice of the comminution machinery resulting in a more favourable size distribution of the processed feedstock could additionally improve the safety aspect. Temperature is an important parameter both due to its influence on the drying process and its influence on the flow rate of the drying agent, since it changes the density of the drying agent and also has some impact on the hydraulic resistance to the bed itself. Too low temperature would increase the residence time and too high could additionally amplify non-uniform drying of the particles of different sizes.

On the other hand, high temperature and high flow rate of drying air enhances cracking of the particles, which could be beneficial in terms of the grindability of dried lignite. From the energy efficiency perspective, it seems to be beneficial to maximize the difference between the relative humidity of the drying agent at the outlet and the inlet to the dryer. This may give some additional safety related benefits mentioned above (water vapours have inerting properties). Moreover, the highest possible relative humidity seems beneficial in the case when latent heat is to be at least partially recovered in a heat exchanger, following the dryer. If the designed dryer is to be located in the power plant, the lowest possible drying temperature would also enhance the latent heat recovery from the flue 
gases, by enabling the use of low quality heat. Same would be true for the heat recovery from cooling water of the condenser. However, in this case temperature of the drying agent would have to be low enough to allow heat exchange, between the drying agent taken from the ambient and cooling water out of the condenser. In both of the cases trade-off would be the size of heat exchangers as well as the size of the dryer itself and consumption of the electricity for auxiliaries, such as blowers.

Specifically, from the feedstock point of view, it seems important to note that the differences between the properties of the different types of lignite and the different results from the drying tests imply structural differences between the tested species. Moreover, it seems that an ash content might be a valuable indicator of the similarity between two different types of lignite and its behaviour during drying.

Drying using air at the lower range of temperatures proved that much greater residence time would be needed in order to achieve a desired moisture content. This would imply a comparably bigger dryer in order to achieve similar capacity. However, specific energy required to remove $1 \mathrm{~kg}$ of water was a subject of a significant increase at the high range of drying temperatures. In general, the study proved the feasibility of using low quality waste heat. Nonetheless, the necessity for the individual approach to each type of lignite cannot be overlooked and the optimization of the temperature of the drying agent should be done on a case to case basis. Most of the types of lignites enabled the possibility to achieve a final moisture content of $20 \%$, with the exception of the Australian lignite, for which moisture content of $35 \%$ seems to be a better target value, where drying in toroidal bed is considered. In case of this type of lignite, using a different drying principle, other than toroidal bed might be a better choice.

Higher temperatures would definitely be beneficial in terms of the required residence time and they seem to be possible to achieve, with the starting point of thermal decomposition being the only limitation. On the other hand, higher temperatures would limit the option to use the heat from the outlet of boiler flue gases, thus having a detrimental influence on the efficiency of the whole system as far as the integration with the lignite fired power plant is considered.

\section{Conclusions}

The conducted study has conclusively proven the feasibility of the use of low temperature heat source (below $80^{\circ} \mathrm{C}$ ) for drying of lignite in a toroidal bed. The moisture content of $20 \%$ could be achieved for most of the tested lignites, using a toroidal bed, with reasonably short residence times (approx. $30 \mathrm{~min}$ ) and air temperatures as low as $60^{\circ} \mathrm{C}$, which seems to be the optimum temperature for most of the lignites, with respect to energy consumption and residence time. Australian lignite is an exception and in this case, optimum temperature of the drying agent seems to be $50{ }^{\circ} \mathrm{C}$, as the average drying rate for higher temperatures was not significantly different. Additionally, it should not be overlooked that the change of the particle size distribution, to some extent, affected the final moisture content due to the entrainment of wet, fine particles.

Performed experiments showed that, for the same conditions in the toroidal bed, different types of lignite might exhibit different behavior. Differences in terms of the drying kinetics were clearly observed. Furthermore, each of the lignites exhibited differences between their initial and final particle size distribution. However, these differences could not be explained solely by the loss of water and by the shrinkage of the particles during drying. Moreover, investigation using SEM revealed attrition of the particles of dried lignites leading to formation of cracks. In-bed attrition, leading to comminution of the particles within the toroidal bed, consequently caused the entrainment of smaller particles, which subsequently caused problems with their drying. In an industrial installation, recirculation of fine particles should be taken into consideration. Moreover, the aforementioned attrition might introduce additional counter-measures related with possible explosion hazards. 
Author Contributions: Following contributions have been made by individual authors. Conceptualization: H.P.-K. and M.C.; methodology: H.P.-K. and M.C.; investigation: M.C.; formal analysis: M.C.; data curation: M.C., L.N.; writing—original draft preparation: L.N.; writing—review and editing: E.K., I.V., I.A., P.G., H.P.-K., L.N.; visualization: M.C.; supervision: H.P.-K., P.G., E.K.; project administration: H.P.-K., P.G., E.K.; funding acquisition: H.P.-K., P.G., E.K.

Funding: The scientific work described in the present paper has been performed within the DRYLIG project, which is co-funded through the Research Fund for Coal and Steel of the European Commission under research grant No RFCR-CT-2014-00009. The support of the Polish Ministry of Science and Higher Education (agreement no. 3170/CES/2014/2) is also gratefully acknowledged.

Acknowledgments: Help of the Institute of Combustion and Power Plant Technology (IFK) of the University of Stuttgart with pre-crushing of the samples of lignite is gratefully acknowledged.

Conflicts of Interest: The authors declare no conflict of interest.

\section{References}

1. The International Energy Agency IEA Coal Information. Coal Inf. Overv. 2017.

2. EURACOAL. Coal Industry Across Europe, 6th ed.; European Association for Coal and Lignite AISBL: Brussels, Belgium, 2017.

3. Pawlak-Kruczek, H. 2-Properties of low rank coals and resulting challenges in their utilization. In Low-Rank Coals for Power Generation, Fuel and Chemical Production; 2017; pp. 23-40. ISBN 9780081008959.

4. Jóźwiak, W.; Kalewska, B.; Łoziński, M.; Mitura, Z.; Sieciński, J.; Wiśniewska, G. Nawóz organiczno-mineralny i sposób wytwarzania nawozu organiczno-mineralnego. Polish Patent PL 209547, 2008.

5. Park, J.H.; Lee, C.H.; Park, Y.C.; Shun, D.; Bae, D.H.; Park, J. Drying Efficiency of Indonesian Lignite in a Batch-Circulating Fluidized Bed Dryer. Dry. Technol. 2014, 32, 268-278. [CrossRef]

6. Si, C.; Wu, J.; Wang, Y.; Shang, X.; Zhang, Y.; Liu, G. Experimental study on three-stage microwave-assisted fluidized bed drying of Shengli lump lignite. Dry. Technol. 2016, 34, 685-691. [CrossRef]

7. Song, Z.; Yao, L.; Jing, C.; Zhao, X.; Wang, W.; Ma, C. Drying behavior of lignite under microwave heating. Dry. Technol. 2017, 35, 433-443. [CrossRef]

8. Pusat, S.; Erdem, H.H. Drying characteristics of coarse low-rank-coal particles in a fixed-bed dryer. Int. J. Coal Prep. Util. 2017, 37, 303-313. [CrossRef]

9. Yang, Y.; Jing, X.; Li, Z.; Liu, X.; Zhang, Y.; Chang, L. Effect of Drying Conditions on Moisture Re-Adsorption Performance of Dewatered Lignite. Dry. Technol. 2013, 31, 1430-1437. [CrossRef]

10. Feng, L.; Tang, J.; Ma, Z.; Wan, Y. Effect of mechanical thermal expression drying technology on lignite structure. Dry. Technol. 2017, 35, 356-362. [CrossRef]

11. Wen, Y.; Liao, J.; Liu, X.; Wei, F.; Chang, L. Removal behaviors of moisture in raw lignite and moisturized coal and their dewatering kinetics analysis. Dry. Technol. 2017, 35, 88-96. [CrossRef]

12. Pawlak-Kruczek, H.; Plutecki, Z.; Michalski, M. Brown Coal Drying in a Fluidized Bed Applying a Low-Temperature Gaseous Medium. Dry. Technol. 2014, 32, 1334-1342. [CrossRef]

13. Agraniotis, M.; Stamatis, D.; Grammelis, P.; Kakaras, E. Numerical investigation on the combustion behaviour of pre-dried Greek lignite. Fuel 2009, 88, 2385-2391. [CrossRef]

14. Tahmasebi, A.; Zheng, H.; Yu, J. The influences of moisture on particle ignition behavior of Chinese and Indonesian lignite coals in hot air flow. Fuel Process. Technol. 2016, 153, 149-155. [CrossRef]

15. Drosatos, P.; Nikolopoulos, N.; Nikolopoulos, A.; Papapavlou, C.; Grammelis, P.; Kakaras, E. Numerical examination of an operationally flexible lignite-fired boiler including its convective section using as supporting fuel pre-dried lignite. Fuel Process. Technol. 2017, 166, 237-257. [CrossRef]

16. Komatsu, Y.; Sciazko, A.; Zakrzewski, M.; Kimijima, S.; Hashimoto, A.; Kaneko, S.; Szmyd, J.S. An experimental investigation on the drying kinetics of a single coarse particle of Belchatow lignite in an atmospheric superheated steam condition. Fuel Process. Technol. 2015, 131, 356-369. [CrossRef]

17. Pusat, S.; Akkoyunlu, M.T.; Erdem, H.H.; Dağdaş, A. Drying kinetics of coarse lignite particles in a fixed bed. Fuel Process. Technol. 2015, 130, 208-213. [CrossRef]

18. Sciazko, A.; Komatsu, Y.; Zakrzewski, M.; Akiyama, T.; Hashimoto, A.; Shikazono, N.; Kaneko, S.; Kimijima, S.; Szmyd, J.; Kobayashi, Y. Experimental Attempts to Investigate the Influence of Petrographic Properties on Drying Characteristics of Lignite in Superheated Steam Atmosphere. Energies 2016, 9, 371. [CrossRef] 
19. Stokie, D.; Woo, M.W.; Bhattacharya, S. Attrition of Victorian brown coal during drying in a fluidized bed. Dry. Technol. 2016, 34, 793-801. [CrossRef]

20. Shu, J.; Lakshmanan, V.I.; Dodson, C.E. Hydrodynamic study of a toroidal fluidized bed reactor. Chem. Eng. Process. Process Intensif. 2000, 39, 499-506. [CrossRef]

21. Law, R.; Ramshaw, C.; Reay, D. Process intensification-Overcoming impediments to heat and mass transfer enhancement when solids are present, via the IbD project. Therm. Sci. Eng. Prog. 2017, 1, 53-58. [CrossRef]

22. Zhang, W. A Review of Techniques for the Process Intensification of Fluidized Bed Reactors. Chin. J. Chem. Eng. 2009, 17, 688-702. [CrossRef]

23. Gonzalez-Quiroga, A.; Reyniers, P.A.; Kulkarni, S.R.; Torregrosa, M.M.; Perreault, P.; Heynderickx, G.J.; Van Geem, K.M.; Marin, G.B. Design and cold flow testing of a Gas-Solid Vortex Reactor demonstration unit for biomass fast pyrolysis. Chem. Eng. J. 2017, 329, 198-210. [CrossRef]

24. De Wilde, J. Gas-solid fluidized beds in vortex chambers. Chem. Eng. Process. Process Intensif. 2014, 85, 256-290. [CrossRef]

25. Ekatpure, R.P.; Suryawanshi, V.U.; Heynderickx, G.J.; de Broqueville, A.; Marin, G.B. Experimental investigation of a gas-solid rotating bed reactor with static geometry. Chem. Eng. Process. Process Intensif. 2011, 50, 77-84. [CrossRef]

26. Niyogi, K.; Torregrosa, M.M.; Pantzali, M.N.; Heynderickx, G.J.; Marin, G.B. Experimentally validated numerical study of gas-solid vortex unit hydrodynamics. Powder Technol. 2017, 305, 794-808. [CrossRef]

27. Trujillo, W.R.; De Wilde, J. Influence of solids outlets and the gas inlet design on the generation of a gas-solids rotating fluidized bed in a vortex chamber for different types of particles. Chem. Eng. Sci. 2017, 173, 74-90. [CrossRef]

28. Reay, D.A. Heat transfer enhancement-A review of techniques and their possible impact on energy efficiency in the U.K. Heat Recover. Syst. CHP 1991, 11, 1-40. [CrossRef]

29. Wang, H.; Mustaffar, A.; Phan, A.N.; Zivkovic, V.; Reay, D.; Law, R.; Boodhoo, K. A review of process intensification applied to solids handling. Chem. Eng. Process. Process Intensif. 2017, 118, 78-107. [CrossRef]

30. Blissett, R.; Sommerville, R.; Rowson, N.; Jones, J.; Laughlin, B. Valorisation of rice husks using a TORBEDï $i \frac{1}{2}$ combustion process. Fuel Process. Technol. 2017, 159, 247-255. [CrossRef]

31. Chen, T.T.; Dutrizac, J.E. Characterization of the Calcines Produced by the Roasting of Zinc Sulphide Concentrates in a Torbed Reactor. Can. Metall. Q. 2003, 42, 1-16. [CrossRef]

32. McDonough, J.R.; Law, R.; Reay, D.A.; Zivkovic, V. Intensified carbon capture using adsorption: Heat transfer challenges and potential solutions. Therm. Sci. Eng. Prog. 2018, 8, 17-30. [CrossRef]

33. Batcha, M.F.M.; Salleh, H.; Raghavan, V.R. Studies on Biomass Drying Apparatus Using Swirling Fluidization Technique. In Proceedings of the MUCEET 2009 Malaysian Technical Universities Conference on Engineering and Technology, Kuantan, Pahang, Malaysia, 20-22 June 2009; p. 5.

34. Nikolopoulos, N.; Violidakis, I.; Karampinis, E.; Agraniotis, M.; Bergins, C.; Grammelis, P.; Kakaras, E. Report on comparison among current industrial scale lignite drying technologies (A critical review of current technologies). Fuel 2015, 155, 86-114. [CrossRef]

35. Karthikeyan, M.; Zhonghua, W.; Mujumdar, A.S. Low-Rank Coal Drying Technologies—Current Status and New Developments. Dry. Technol. 2009, 27, 403-415. [CrossRef]

36. Si, C.; Wu, J.; Wang, Y.; Zhang, Y.; Shang, X. Drying of Low-Rank Coals: A Review of Fluidized Bed Technologies. Dry. Technol. 2015, 33, 277-287. [CrossRef]

37. Atsonios, K.; Violidakis, I.; Agraniotis, M.; Grammelis, P.; Nikolopoulos, N.; Kakaras, E. Thermodynamic analysis and comparison of retrofitting pre-drying concepts at existing lignite power plants. Appl. Therm. Eng. 2015, 74, 165-173. [CrossRef]

38. Nenad Sarunac; Mark Ness. Charles Bullinger Improve Plant Efficiency and Reduce $\mathrm{CO}_{2}$ Emissions When Firing High-Moisture Coals. Available online: http:/ / www.powermag.com/improve-plant-efficiency-andreduce-co2-emissions-when-firing-high-moisture-coals / (accessed on 15 April 2018).

39. Bullinger, C.; Ness, M.; Sarunac, N. Coal Creek Prototype Fluidized Coal Dryer: Performance Improvement, Emissions Reduction and Operating Experience. In Proceedings of the 31st International Technical Conference on Clean Coal \& Fuel Systems, Clearwater, FL, USA, 5-9 June 2006.

40. Sarunac, N.; Bullinger, C.W.; Ness, M. Four Years of Operating Experience with DryFining TM Fuel Enhancement Process at Coal Creek Generating Station. J. Energy Power Eng. 2015, 9, 526-538. [CrossRef] 
41. Pawlak-Kruczek, H.; Ostrycharczyk, M.; Plutecki, Z. Potential and Possibilities for Improving Power Unit Efficiency and Reducing Greenhouse Gas Emission. In Proceedings of the XIII International Scientific and Technical Conference, Thermal Power Plant Operation Modernization Rehabilitation, Słok, Bełchatów, Poland, 31 May-2 June 2017.

42. Agraniotis, M.; Karellas, S.; Violidakis, I.; Doukelis, A.; Grammelis, P.; Kakaras, E. Investigation of pre-drying lignite in an existing Greek power plant. Therm. Sci. 2012, 16, 283-296. [CrossRef]

43. Akkoyunlu, M.T.; Erdem, H.H.; Pusat, S. Determination of economic upper limit of drying processes in coal-fired power plants. Dry. Technol. 2016, 34, 420-427. [CrossRef]

44. Agraniotis, M.; Koumanakos, A.; Doukelis, A.; Karellas, S.; Kakaras, E. Investigation of technical and economic aspects of pre-dried lignite utilisation in a modern lignite power plant towards zero $\mathrm{CO}_{2}$ emissions. Energy 2012, 45, 134-141. [CrossRef]

45. Xu, C.; Xu, G.; Zhao, S.; Zhou, L.; Yang, Y.; Zhang, D. An improved configuration of lignite pre-drying using a supplementary steam cycle in a lignite fired supercritical power plant. Appl. Energy 2015, 160, 882-891. [CrossRef]

46. Chen, H.; Qi, Z.; Chen, Q.; Wu, Y.; Xu, G.; Yang, Y. Modified high back-pressure heating system integrated with raw coal pre-drying in combined heat and power unit. Energies 2018, 11, 2487. [CrossRef]

47. Widera, M. An overview of lithotype associations of Miocene lignite seams exploited in Poland. Geologos 2016, 22, 213-225. [CrossRef]

(C) 2019 by the authors. Licensee MDPI, Basel, Switzerland. This article is an open access article distributed under the terms and conditions of the Creative Commons Attribution (CC BY) license (http://creativecommons.org/licenses/by/4.0/). 